Portland State University

PDXScholar

\title{
The spatial patterning of residential differentiation in metropolitan community : the case of Kaohsiung City in Taiwan, 1982
}

Chih-Jen Chen

Portland State University

Follow this and additional works at: https://pdxscholar.library.pdx.edu/open_access_etds

Part of the Demography, Population, and Ecology Commons, and the East Asian Languages and Societies Commons

Let us know how access to this document benefits you.

\section{Recommended Citation}

Chen, Chih-Jen, "The spatial patterning of residential differentiation in metropolitan community : the case of Kaohsiung City in Taiwan, 1982" (1991). Dissertations and Theses. Paper 4284.

https://doi.org/10.15760/etd.6167

This Thesis is brought to you for free and open access. It has been accepted for inclusion in Dissertations and Theses by an authorized administrator of PDXScholar. Please contact us if we can make this document more accessible: pdxscholar@pdx.edu. 
AN ABSTRACT OF THE THESIS OF Chih-Jen Chen for the Master of Science in Sociology presented April 15, 1991

Title: The Spatial Patterning of Residential

Differentiation in Metropolitan Community: The Case of Kaohsiung City in Taiwan, 1982

APPROVED BY MEMBERS OF THE THESIS COMMITTEE:

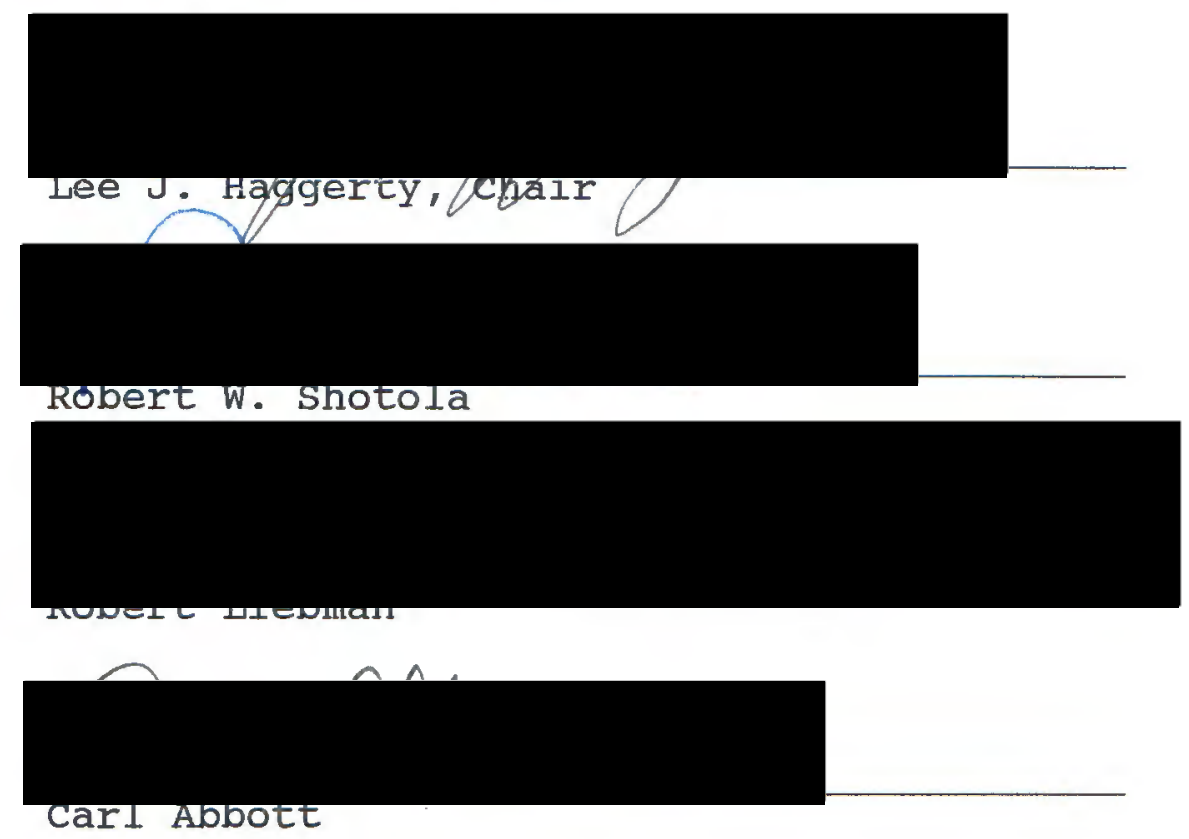

The urban growth process produces a complex sociogeographic division of labor among the component parts of the urban community. During this process, each subarea of the community differentiates from the other parts in its physical and demographic characteristics, becomes specialized functionally and structurally. The spatial 
patterning of the urban community is the result of this differentiation process.

The purpose of this study was to uncover the latent constructs underlying the ecological dimensions of Kaohsiung city in Taiwan. Factorial ecology was employed to discover the underlying factors. An array of forty-nine demographic, socioeconomic, and crime variables were collected and input in the factor analysis, and, finally, seven underlying factors were extracted. The seven underlying factors differentiating the ecological structure of Kaohsiung city are professional, commercial activity, disadvantageous opportunity, vice, female labor participation, disability, and employment opportunity. The cumulative eigen values account for $56 \%$ of the variation in the 49 variables selected for analysis.

With respect to the spatial distribution of these seven socio-economic underlying factors, the technique of two-way analysis of variance was applied to examine the concentric zone and sector models. Among these seven underlying factors, five show significance in concentric zone and sector organization as well as significant zone-sector interaction effects, and the other two are significani in only the concentric model. The five which appear to be organized both sectorialiy and zonally are: professionals, commercial activity, disadvantageous opportunity, vice and employment opportunity. Female labor participation and 
disability are only organized concentrically, in terms of the analytical findings of two-way ANOVA.

The research findings of analysis of variance in examining the spatial patterning of the socio-economic underlying constructs show that both the concentric zone model and sector model can explain some of the spatial patterning in Kaohsiung city. Moreover, the interaction effects between concentric zone and sector are also significant. Such findings reflect a unique land use pattern in Taiwan--multiple and mixed zoning. 
THE SPATIAL PATTERNING OF RESIDENTIAL DIFFERENTIATION IN METROPOLITAN COMMUNITY: THE CASE OF

KAOHSIUNG CITY IN TAIWAN, 1982

\author{
by \\ CHIH-JEN CHEN
}

A thesis submitted in partial fulfillment of the requirements for the degree of

\author{
MASTER OF SCIENCE \\ in \\ SOCIOLOGY
}

Portland Stace University

1991 
TO THE OFFICE OF GRADUATE STUDIES :

The members of the committee approve the thesis of Chih-Jen Chen presented April 15. 1991.
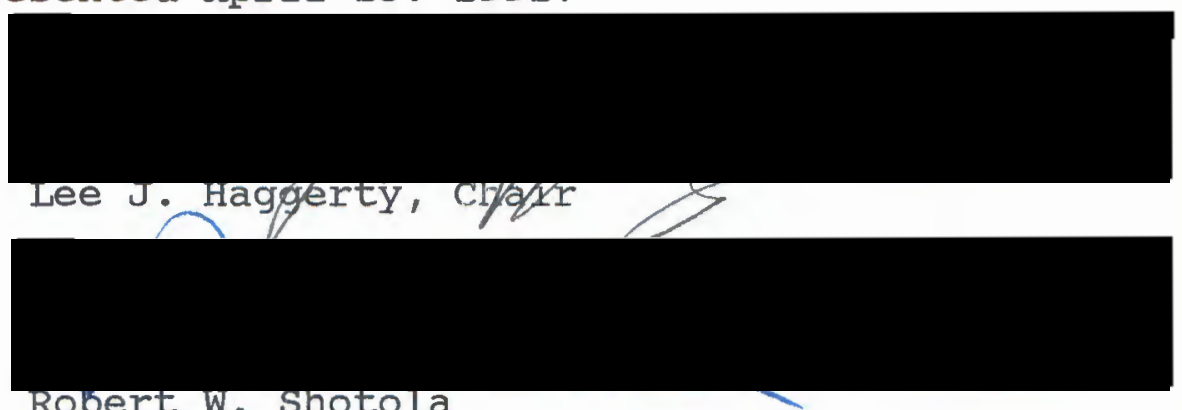

Robert W. Shotola

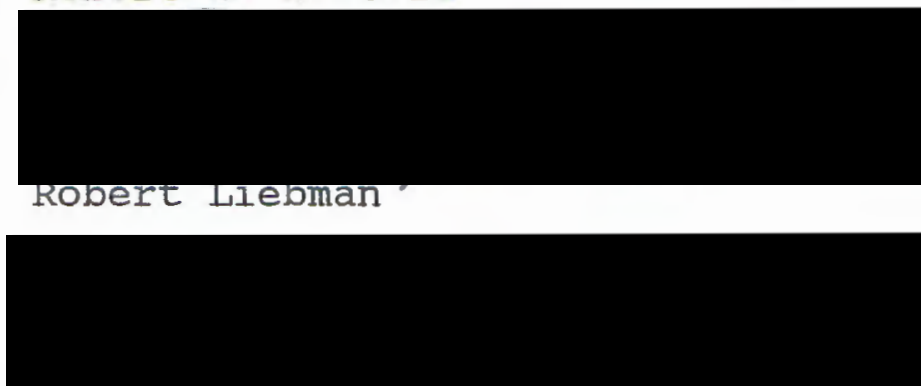

Car1 Abbott

APPROVED:

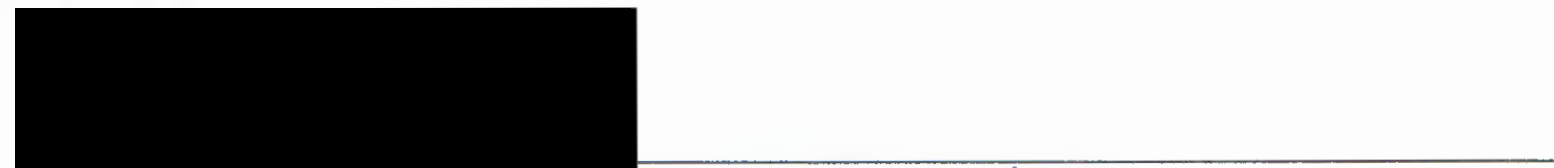

Grant M. Farr, Head, Department of Sociology

C. William Savery, Vice Provest for Graduate studies and Research 
TABLE OF CONTENTS

PAGE

LIST OF TABLES $\ldots \ldots \ldots \ldots \ldots \ldots \ldots \ldots \ldots \ldots \ldots \ldots \ldots$

LIST OF FIGURES..................... vi

CHAPTER

I INTRODUCTION................... 1

Perspective of the study.......... 4

Overview of the study............ 7

II SPATIAL PATTERNING IN THE URBAN CITY--A

LITERATURE REVIEW............... 9

Urbanism as a Way of Life.......... 9

Classical Theory of the Anatomy

of the City.................. 12

Concentric Zone Theory

Sector Theory

Multiple-Nuclei Theory

Organizational and Psychological

Persectives on Urban Life........... 22

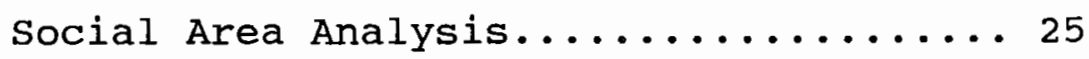

III FACTORIAL ECOLOGY................ 29

Empiricial Findings of Underlying Factors

Differentiating U.S. Cities....... 30

Spatial Distribution of Underlying

Factors...................... 34

Comparative And Developmental Factorial

Ecology................... 38 
IV SPATIAL DISTRIBUTION OF THE RESIDENTIAL AREA:

AN ANALYTICAL FRAMEWORK........... 47

Conceptual Framework: the Application of

Factor Analysis.............. 48

Data Source And Variables.......... 51

A Brief Depiction of the Ecological

Structure in Kaohsiung.......... 54

Administrative And Ecological Hierarchy Urbanization in Taiwan during Last Four Decades

$V$ SPATIAL PATTERNING OF RESIDENTIAL

DIFFERENTIATION IN KAOHSIUNG CITY, 1982..68

Factors Underlying Residential

Differentiation: Results of

Factor Analysis.............. 69

Spatial Patterning of Residential

Differentiation: Results of

Analysis of Variance.......... 86

VI CONCLUSION.......................... 105

Summary of Findings............... 105

Discussion and Implication

of Research Findings........... 106

REFERENCES........................... 110

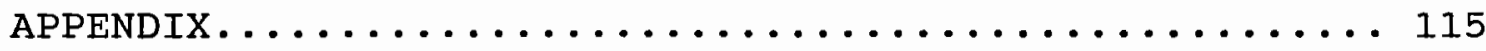




\section{LIST OF TABIES}

TABLE

PAGE

I Definitions of Variables............. 55

II Rotated Factor Pattern of Underlying spatial

Factors in Kaohsiung city, 1982..... 75

III Mean Scores of Underlying Socioeconomic

Factors by concentric Zone and

Sector in Kaohsiung City...........93

IV Two-Way ANOVA of Underlying Factors by

Concentric Zone and Sector.......... 100 


\section{LIST OF FIGURES}

1. Administrative system in Taiwan..........6 62

2. Administrative classification of Kaohsiung

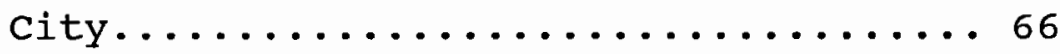

3. Scree Plot of Eigenvalues for

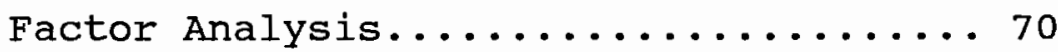

4. Concentric Circles in Kaohsiung

Municipality................... 89

5. Sectoral Zones in Kaohsiung

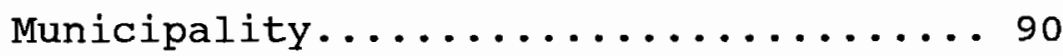

6. Major Establishments in Kaohsiung

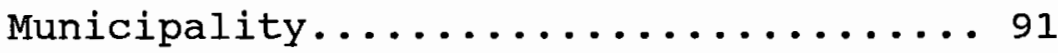


CHAPTER I

INTRODUCTION

The urban growth process produces a complex sociogeographic division of labor among the component parts of the urban community. During this process, each subarea of the community differentiates from the other parts in its physical and demographic characteristics, becomes specialized functionally and structurally. The spatial patterning of the urban community is the result of this differentiation process.

The ecological approach to urban analysis was developed to understand how these component parts are organized into a recognizable and integrated ecological entity. Most classical ecological research has been devoted to mapping and analyzing the spatial and symbiotic relationships among the component parts of the urban community. When multivariate analysis was adapted to conduct urban analysis, it led to the burgeoning of urban ecology. More complicated and sophisticated techniques of analysis are employed in the ecological approach currently.

The ecological approach primarily focuses on the spatial patterning of human activities in the urban community. The basic rationale is that in the urban 
community human activities are segregated by certain socioeconomic attributes such as occupation, social status, income, life style, race, ethnicity, and so on. The distribution of these socio-economic characteristics is reflected in the spatial dimension in the city. Hence, spatial patterning of socio-economic characteristics becomes the central concern of sociological study. Spatial patterning can be seen in the differentiation of residence, communication and transportation systems, and the spatial distribution of socio-economic activities.

In western societies, much of the variation in the social and economic characteristics of urban communities may be interpreted in terms of some underlying constructs, particularly differences in socio-economic status, in family composition, and in ethnicity. These constructs are in turn related to spatial patterning. Sociological research supports two important conclusions. First, the spatial patterns of socio-economic characteristics had been repeatedly discussed in Western cities. Second, these spatial patterns are found to be consistent with ecological models. The adoption of more sophisticated multivariate analyses, for example, factor analysis and latent structure analyses, further supports the association between the spatial patterning of socioeconomic characteristics suggested by ecological models. 
However, the predicted patterns are not found in nonWestern societies, especially in Asia. Other factors were found to underlie the spatial patterning of socio-economic life in non-Western urban communities. In Kaohsiung's case, special cultural attributes such as family relationship, ethnicity, and housing pattern may play an important role on its spatial patterning. The strong family relationship restricts individual's geographic mobility. Because both parents and children tend to live nearby for greater social interaction. The family usually takes care of the disabled members and discourages women from working. The single ethnicity in Taiwan cannot create race segregation. The people in Kaohsiung generally live in apartments, and there are very few single houses in the city. Mixed zoning probably makes less distinction among commercial, residential and industrial areas. All of these factors may influence the spatial patterning in Kaohsiung city.

on the other hand, economic attributes may still play an important role in non-western cities, especially in a fast developing country as Taiwan. Because the developing process is basically driven by the economic force, there should be some predicable effects which are the same as the findings in western cities. This implies a need for sociology to construct one or more non-Western social ecologies to interpret the differentiation of socio-economic structure in Asian, African, and Latin American cities. 
There are few empirical studies of non-western cities in the literature. Studies of non-western cities applying newer techniques are especially necessary. The primary objective of this study was to examine urban spatial patterning in Taiwan, a non-western and newly industrialized society. By providing an empirical study of a non-western city, it will add to sociologists' knowledge about urban spatial patterning in a newly developed country. Moreover, this study provides a data point to compare the spatial patterning of cities in under-developed, developing and developed countries.

\section{PERSPECTIVE OF THE STUDY}

The target city of this study is Kaohsiung, one of the two primary metropolises in Taiwan, Republic of China. Taiwan has moved into the category of developed countries recently. There are many studies describing and exploring the success story about economic progress on this island. Nevertheless, few systematic observations have been made about the social activities of its people. As a newly industrialized country, Taiwan indeed provides an excellent "natural laboratory" which can be employed to analyze the interplay of human activities and socio-economic development.

Moreover, Kaohsiung's case can provide an empirical test of Western sociological theories, because it 
experienced different urban development from western cities. First, the timing and speed of urbanization of Kaohsiung are different. Because of special historical background, population increased approximately from 300,000 to $1,200,000$ from 1950 to 1990. Western cities generally grew at a slower pace over a longer period.

Second, the spatial patterning differs because of difference in zoning and residential segregation. With respect to zoning, western cities tend to specialize functionally to some extent from zoning constraints. However, Kaohsiung has no planned specialization except for military regions, industrial parks, and free exporting zones. Western cities have residential segregation by races and by various socio-economic groups. Nevertheless, there is only one race in Kaohsiung or even in Taiwan. Besides, there is little urban planning applied to Kaohsiung during the modernization period. Various socioeconomic groups tend to live in the same area.

Third, the military community has an important influence on socio-economic segregation in Kaohsiung. For these reasons, Kaohsiung is an interesting case which may be different from western cities in spatial patterning. In this study, the primary objective was to concentrate on the spatial patterning that underlies human activities in the urban community. While the empirical findings in American cities show a consistent trend, the situations in non- 
American cities, especially in non-Western cities, still remain unclear. It is the objective of this study to analyze a Taiwanese city as a supplement to the factorial ecology at Asian cities.

Specifically, two primary goals were pursued. In the first step, factor analysis was adopted to uncover the latent structure differentiating spatial patterns of socioeconomic life of residents in the city. That is, following the literature of urban ecology, the urban community is neither an undifferentiated collection of people or a haphazard collection of activities. There are certain latent structural constructs which underlie the spatial pattern of socio-economic characteristics among groups and activities in the city. The application of factorial ecology provides an appropriate tool for revealing these latent organizing factors.

Once the latent or underlying constructs of socioeconomic life were uncovered, interest turned to explore the association between the spatial patterning of the factors and ecological models. In other words, the goal was to examine the correspondence between human activities and geographical location. The rationale is that human activities typically reflect or are projected spatially by ecological forces and limitations. Analysis of variance of the latent structural factors was performed to examine the association between socio-economic factors and ecological 
locations, with particular attention to evaluating two competing ecological models--concentric zones and sectors.

\section{OVERVIEW OF THE STUDY}

The theme of Chapter II will focus on the theories of spatial patterning in the city. It will first discuss Wirth's social-psychology model of urbanism. Then it will delineate the classical ecological approach of the concentric zone model, sector model, and multiple-nuclei model. The second part of the chapter will discuss the social area approach in detail, for it has provided most fruitful insights into the understanding of social ecology in urban communities.

Chapter III will discuss factorial ecology. Classical and comparative studies driven by factorial ecology will be examined sequentially, and the application of factorial ecology in sociology will be discussed.

Chapter IV will discuss research design and methodology. A conceptual framework for studying spatial patterning in Kaohsiung city will be formulated. Availability of data sources, variable definitions and measurement are the central concerns in this chapter. A brief description of socio-economic and urban development in Taiwan and Kaohsiung city during last several decades will be provided. 
The socio-economic spatial patterning in Kaohsiung city derived from the findings of factor analysis will be presented in Chapter $\mathrm{V}$. Discussion and interpretation of the results of factor analysis are also provided. The association between the spatial differentiation and ecological location models is addressed. The second part of this chapter is devoted to the examination of analysis of variance in the socio-economic dimension patterning suggested by ecological models.

Finally, Chapter VI summarizes the findings of this study of differentiation in Kaohsiung City, and then discusses the implications of these research findings. 
CHAPTER II

SPATIAL PATTERNING IN THE URBAN CITY--A LITERATURE REVIEW

Since the beginning of American sociology, urban life has occupied a central place in both theories and empirical research. The growth of the urban community involves the spatial redistribution of population and land use activities. Correspondingly, there are two sociological approaches exploring modern urban life. One is the socialpsychological approach of Louis Wirth (Wirth, 1938). The other is urban ecology, including the classical chicago school, social area analysis, factorial ecology, and comparative studies of urban structure.

\section{URBANISM AS A WAY OF LIFE}

In his famous article "Urbanism as a Way of Life," Louis wirth proposed the widely accepted theory of the effects of cities on social relationships (Wirth, 1938). He accepted the definition of the city as a point of population concentration of large size, high density, and heterogeneity of inhabitants. Derived from these attributes, wirth considered the pattern of social interaction and the consequences for organized social life to be: isolation, the 
decline of primary group membership, and the dominance of formal organizations.

Wirth felt that the greater size of the urban population, the greater volume of social interaction. With increased amounts of social interaction, the degree of interdependence among particular individuals would be less since interpersonal dependence was spread over more people. As a result, contacts became impersonal, superficial, and transitory. In addition, high population density produced frequent physical contacts, fast-paced living, functional segregation of urban sub-areas, and segregation of people into a residential mosaic in which residents of sub-areas had some degree of homogeneity. Finally, the greater heterogeneity of new cities was believed by wirth to produce distinctive effects. Lacking a common background, diverse people would tend to place emphasis on visual recognition and symbolism. Such things as place of residence thus became status symbols. With no common values or ethical systems, money tended to become their sole measurement of wealth. However, economic class distinctions were predisposed to break down, because city dwellers belonged to a variety of sub-groups, a further consequence was the growth of mass political movements and of pluralistic interest groups within the city.

Wirth's model was based on two theories: a structural one drawn from Durkheim and a social-psychological one based 
upon simmel. Following structural theory, size, density, and heterogeneity, were considered to lead sequentially to differentiation, formalization of institutions, and anomie. on the psychological level, urbanism was thought to cause the possibility of psychological overload. The city held out opportunities for great mobility, and brought social isolation and deviance. In sum, urbanization inevitably led to social malaise in Wirth's view.

While Wirth's theory connected urbanism with negative effects, it suggested a connection among size, density, intra-regional homogeneity, inter-regional heterogeneity, and structural differentiation which became fundamental ideas of the later ecological approaches. Following the Chicago tradition, ${ }^{1}$ wirth paid lots of attention to how people--the residents of city--interacted within the territory of the urban community, and how other social, economic, racial, and physical factors affected people's interaction. Moreover, Wirth provided an insightful depiction about the social, economic, and ecological structures of the city from the perspective of social psychology. That is, not only did wirth provide a microscopic and socio-psychological analysis of the urban

${ }^{1}$ Louis Wirth was among the earlier cohort of graduate students at Chicago, and he studied under Robert Park and Ernest Burgess. Thus, it is not surprising that he shared the common interests and ideas of human ecology which characterized the "Chicago School" of urban sociology. Also, his studies influenced the faculty and students at Chicago heavily. 
community, but he also made an effort to construct the linkage between the micro and macro dimensions of urban community. These understandings have been employed by human ecologists to be the basic assumptions of how human activities and orientations are organized. Based on such presumptions, human ecologists began to analyze the ecological aspects of the city.

\section{CLASSICAL THEORY OF THE ANATOMY OF THE CITY}

At first glance, the parts of the city present a spectrum of variation along the dimension of physical structure, functional activities, residential patterns, and socio-economic composition. Segregation is the term applied to such phenomenon, and this conception was an important and basic element of human ecology (Mckenzie, 1926; and Park, 1936). While the notion of segregation implies a social, particularly racial, differentiation within the city, it also can be employed as a conceptual tool to analyze other attributes of the city. For example, sustenance activities, occupational patterns, building structures, and patterns of crime and delinquency, have all been seen to have a segregative appearance. In fact, the classical urban studies, especially of Chicago school, were largely interested in the manifestation of segregation in the city. However, with the emergence of the ecological approach, investigators studied segregation in terms of spatial 
patterns. That is, the unit of concern to these investigators shifted from the individual actors and groups to territorially based areas. The concern was focused on the spatial organization of human activities in urban space. ${ }^{2}$ There are three classic models or theories which best exemplify this approach. They are Burgess's concentric zone model, Hoyt's sector theory, and Harris and Ullman's multi-nuclei theory.

Concentric Zone Theory

Based on his research on metropolitan Chicago, Ernest W. Burgess contributed the theory of concentric zones of urban growth and differentiation (Burgess 1925). Burgess suggested that growth and differentiation of metropolitan areas in America occurred in gradually extended concentric zones, each characterized by a typical pattern of land use. These zones emerged as the result of expansion outward from the central business district of the central city. The central business district $(C B D)$ is the initial zone of commercial, social and civic life, comprised of skyscrapers, hotels, department stores, light manufacturing, and commercialized leisure. It is basically not a residential district. Encircling the downtown retail district is the

${ }^{2}$ For more detailed discussion of human ecology, see Mckenzie's (1926) and Park's (1936) articles which have been mentioned above. In addition, Hawley's (1950) Human Ecology: A Theory of community structure is a classic in this field. 
wholesale business district. The second zone is called the zone of transition, because it is subject to change caused by encroaching business and industrial land uses expanding beyond the CBD. In Burgess's view, this zone has a mixture of residential and nonresidential uses. The residents tend to be a heterogeneous assortment of low-income groups, immigrants, and unconventional types including social outcasts such as prostitutes, addicts, or criminals, interspersed with some high-income groups living in the luxuriously roomy apartments. The nonresidential uses are the business and light manufacturing that encroach on the residential district. The third zone is the zone of independent workingmen's homes, occupied mainly by secondgeneration immigrant blue-collar workers. They are higher in socioeconomic status than most of the zone of transition dwellers, but they are still not fully assimilated into the middle class. In many American cities, the third zone is inhabited largely by colonies of recent immigrants. Zone four is the zone of middle class dwellers, comprised of mainly professional people, small business persons, managerial types, and other white-collar workers. It is made up of single-family dwellings and high-class apartment buildings. The fifth zone, the commuter zone, is the area often consisting of suburbs or satellite cities on the outer periphery of the central city. In large metropolitan areas, the fifth zone may form a ring from thirty to sixty miles 
beyond the central business district. The name "commuter's zone", in Burgess's term, implies an efficient transportation network allowing city workers to arrive daily from, and to leave nightly to bedroom communities beyond the political boundaries of the central city.

In short, the zonal model of urban growth and structure is put forward as an ideal or constructed type rather than as a substantive generalization. It provides a picture of urban development as it would occur if only one factor, competition for access to the city center, determined the pattern of urban growth as the city expands from the center outward.

Since Burgess's original paper, there has been a considerable amount of research supporting or refuting the concentric zone theory (Alihan, 1938; Davis, 1937; Quinn, 1940; Haggerty, 1971). However, Burgess did not insist that his theory was empirically accurate as a physical description of any given city, and he recognized that physical barriers, such as lakes, hills, rivers, or transportation lines, could produce departures from his model. The theory is an idealized conceptualization designed to identify in dynamic terms the general process of city growth and differentiation over time, with minor variations, in most modern industrial cities in the United states. 
Sector Theory

Hoyt modified Burgess's concentric zone theory by suggesting that development of the city, rather than occurring in rings around the $\mathrm{CBD}$, tends to follow a pattern of sector growth along the major transportation arteries outward from the center (Hoyt, 1939). This process creates a pattern akin to an octopus with tentacles extending in various directions or to a multipointed star. Hoyt assumed that most residential, commercial, and industrial development in urban areas was distributed in a definite pattern within these sectors. He saw the location and movement of various socioeconomic levels of the residential population as the key factor in patterning urban growth. As cities grow in population, upper-income groups move outward along a particular street or transportation line, so that upper-income residential areas tend to be located on the outer edges of the sector. In turn, low-income groups tend to inherit or invade the aging and frequently deteriorating portions of the sector that have been or are being thus abandoned. The theory is similar to the concentric zone theory in that the socioeconomic status of the population varies from low to high as one moves from the center of the city to the periphery. The main difference is that this occurs in sectors shaped like the slices of a pie radiating outward from the center rather than within concentric zones encircling the center of the city. Hoyt's sector theory 
includes the following elements: (1) industrial areas do not develop in a circle around the CBD but follow transportation lines, such as railroads, waterways, highways or freeways; (2) upper-class residential areas first emerge near retail or administrative centers, and tend to follow established commuter routes toward desirable residential sites on scenic high ground or along scenic lakes, rivers, forests, or parkways. They also tend to grow in the direction of the open and undeveloped countryside rather than toward areas restricted by preexisting developed areas or natural barriers.

Hoyt's sector theory, modifying the theory of concentric zones, did not fundamentally challenge the Burgess's model. Instead, it proposed a more elaborate view of urban growth.

\section{Multiple-Nuclei Theory}

Multiple-nuclei theory was developed by Harris and Ullman (Harris and Ullman, 1945). They argued that cities develop around a series of centers serving a variety of different functions, and located at several points within their boundaries, rather than around a single center at the heart of the city. The initial nucleus of the city may be the retail district in a central-place city, the port or rail facilities in a break-of-bulk city, or the factory, mine, or beach in a specialized-function city. Hence, cities may develop retail centers, wholesale centers, 
residential centers, and so on. Each center represents the concentration of a specific activity at a particular location which is probably best for that activity. Harris and Ullman perceived that multiple centers develop as a result of the following four factors: (I) certain activities require specialized facilities, such as water, sewerage, parking, or accessibility, and they tend to concentrate in the vicinity of these facilities, wherever they may be; (2) similar activities benefit from locations close to one another, and they group together for mutual advantage, as in the cases of high fashion retail shops, law offices, and the headquarters of financial institutions; (3) certain unlike activities may be incompatible or detrimental to one another--for example, locating a chemical factory in the middle of a prime residential area would be considered highly offensive to the residents of such an area, and probably would be forbidden by local zoning codes; (4) certain activities are unable to afford the high rents of the most desirable sites. For many activities, such as storage facilities or warehousing, land in the CBD or other chosen locations may be too expensive or may not be sufficiently advantageous to warrant the costs of competing with other potential users for such locations.

The number of nuclei which results from the historical development and operation of localization forces, varies greatly from city to city. The larger the city, the more 
numerous and specialized are the nuclei. The following districts have developed around nuclei in most large American cities. They are the central business district, the wholesale and light-manufacturing district, the heavy industrial district, the residential district, minor nuclei, and suburb and satellite cities.

Multiple nuclei theory does not specify a particular pattern for the distribution of centers within the urban area, but implies instead that each city develops its own special pattern as a result of its unique historical circumstances and functional activities. Thus, there is no typical way in which multiple centers arrange themselves in relationship to one another.

All three of the theories discussed above have been widely accepted by social scientists but not without considerable criticism. Most of the criticism focuses on the assumption that these theories were intended as literal generalized descriptions of the spatial patterning of cities. The multiple-nuclei theory, which does not specify concrete patterns, escapes this particular criticism. But empirical examination of particular cities that do not seem to fit any of these theoretical schemes, especially Burgess's concentric zone theory and to a lesser extent the sector theory, is often cited to cast doubt on their accuracy or validity (Firey, 1947; Davis, 1937; Caplow, 1952). Hawley concludes that criticisms like these have 
been provoked by a too literal interpretation of the zonal hypothesis, and much of the objection might have been obviated as it had been conceived as an ideal typology of growth rather than as a concrete descriptive model (Hawley, 1971, p.101). Moreover, empirical studies have supported the concentric zone theory (Blumenfeld, 1949; Schnore and Jones, 1969). Berry and Kasarda suggest that if the concentric, sector, and multiple-nuclei schemes are conjointly overlaid on the land use and population maps of any city, they may reveal weblike patterns of neighborhoods whose social, physical, and economic patterns exhibit both concentric and axial dimensions. Therefore, it was concluded that these three classic principles of the internal structure of cities are independent, additive descriptions of the social and economic character of neighborhoods in relation to each other and to the whole (Berry and Kasarda, 1977).

In a more detailed description, Berry (1965) suggests that the basic organization of the city's residential fabric may be seen in terms of (1) the axial variation of neighborhoods by socio-economic rank, and (2) the concentric variation of neighborhoods according to family structure. Neighborhood characteristics involving such social rank indicants as type of occupation, educational attainment, income, and house value, vary according to a sectoral pattern. High status individuals search for particular 
amenities, such as views, higher ground, and so on. Lower status individuals live in lower lying areas. Industrialtransportation arteries that radiate from the central business district, together with that district, form the exogenously determined skeleton of the city. Conversely, the distribution of variables which include age structure, women in the labor force, single family housing, and the other family-linked characteristics, vary with distance from the center.

Classical ecology did address several essential issues of studying the city, and it also provided its followers useful basic conceptions and analytical frameworks. Nevertheless, the most valid criticism of the classic ecological theories is perhaps that they focus on unidimensional variables assumed to be distributed within the metropolitan complex; for example, population density, economic function, or employment. These approaches did not provide adequate comprehension of the process and structure of the urban system, and were commonly criticized for its subjective process of selecting the dimension. other important criticism is that most ecological models operated at the biological and physical level to analyze the city, as a result, seriously neglected or at least underestimated, the subjective aspects of the city. For example, in a study of the residential subareas in Boston, Firey found that the continuing significance of Beacon Hill residential area 
could not be understood by ecological economics (Firey, 1950). Therefore, he suggested sentiment and symbolism as important variables which are obviously social as well as cultural attributes and are ignored by previous ecological models.

However, these non-ecological approaches are quite distinctive from this study since they focus on almost completely different dimensions of the urban community. To help the understanding of the spatial dimension of human activities in urban community, the discussion will be focused on the studies being relevant or supplementary to the subjective aspects of the classical ecological models. ORGANIZATIONAL AND PSYCHOLOGICAL PERSPECTIVES ON URBAN LIFE

One theory of urban life, often called compositional theory, focuses on the differing groupings in various urban areas. Herbert Gans, in Urbanism and Suburbanism as Ways of Life, provides the best illustration of the compositional perspective (Gans, 1962). Gans regarded the differences between urban, suburb, and rural areas as based on the characteristics of their residents, such as ethnicity, social class, family composition, and age group. In his view, American cities consist of five types of residents. The first type is cosmopolitans that include artists, writers, inventors, and other professional workers, such as attorneys, professors, and politicians. This type of people 
live by their own professional skills or techniques. Consequently, they have to live in cities since there is no job opportunity in other places. The second type are known as singles, indicating those who are unmarried or married but with no children. Members of this group usually are young, either just graduated from college, university or other schools, or those who graduated for a period of time without intention to marry. Type three are the ethnic villagers, comprised of different races living in their own ethnic enclaves, such as Chinatown, Little Tokyo or Italian town. These people generally have their own cultures, living styles, and values, so they sometimes cannot get along with the cosmopolitans and singles. The fourth type are the deprived, including alcoholics, prostitutes, and the mentally insane. The final type are those who suffered, either being trapped or being downwardly mobile, such as the homeless, the unemployed, and the poor. Generally speaking, the first two types of groups have fewer economic problems, but they experience alienation and isolation. These social problems result from their lack of social integration. This explanation may be traced from Durkheim's suicide theory (Durkheim, 1964). However, the ethnic villagers usually do not have these problems because they live in their own subsocieties. Their difficulties, nevertheless, come from racial discrimination or stereotypes. The fourth and fifth 
groups are actually the causes of the social problems, such as poverty, crime, and anti-societal behavior.

Although Gans's objective in presenting this classification is to illustrate the essence of social problems in cities, this theory introduces a useful perspective on the traits of each social category in urban life. Specifically, people in the urban community consist of various social groups which come from distinctive backgrounds and have different life styles. The social categorization and grouping of the urban residents is closely intertwined with spatial differentiation of the urban life.

Apparently, both the classical ecological approach and the compositional approach imply the multiplicity of characteristics as a key feature of urban life. Furthermore, both of them observed that either the functional mechanisms or the residents in city, are socially categorized and grouped in spatial patterns differentiating the urban community. They suggested that the urban life is a multi-dimensional phenomenon, and the study of it should be started from a multi-variate model. Social area analysis is an important analytical advance, because it offers an alternative approach of multidimensional methodology, and tries to address some criticisms of classical ecological approaches. 
SOCIAL AREA ANALYSIS

The objective of social area analysis is to classify and compare small sections of the metropolitan community on the basis of their main social attributes. Basically, this approach attempts to provide an analytical framework to summarize the underlying organizational dimensions of the city which provide the social differences among the subareas.

The concept and techniques of social area analysis were originated by Shevsky and Williams in a study of Los Angeles (Shevsky and Williams, 1949). In their views, at least three dimensions of differentiation might be required to comprehend significant variations among sub areas. These dimensions are (1) social economic rank, (2) urbanization, and (3) ethnicity. Social economic rank represents the socio-economic status of an area, which is measured by its occupational and educational levels. Urbanization is defined by the family structure of an area. It is evaluated from the fertility rates of women, the proportion of gainfully employed women, and the percentage of the area housing in single family dwelling units. The index of ethnicity is based on the spatial separation of racial and ethnic groups. Since each of these major social dimensions would be revealed through a different set of indices, each might have its own unique pattern of distribution. For instance, one census tract might be high in social economic 
rank and ethnicity, but low in urbanization. Another might be high in ethnicity and urbanization, but low in social economic rank, and so on.

Shevsky and Bell's social area analysis offered a significant revision of the traditional ecological approach. Their small monograph presented a set of theoretical propositions relating ecological variations to culturaltechnological conditions (Shevky and Bell, 1955:3-17). Bell argued that this approach is useful to social scientists, because it provides a simple and systematic method for delineating urban neighborhoods and communities having different social characteristics. In addition to facilitating cross-sectional comparative studies of the social areas, longitudinal study of a given area can also be accomplished with this approach (Bell, 1959). Social area analysis can be used to examine the relationship between the three major dimensions and an almost unlimited variety of measurable phenomena, such as crime rates, rates of mental illness, voting or religious behavior, life styles, and property values.

Moreover, this approach implied the possible relationship between the type and complexity of urban differentiation and the scale of the society. The pattern of social (and physical) differentiation in the cities of preindustrial societies, would be relatively simple and perhaps virtually unidimensional. As the scale of society 
expanded, there would be increased complexity and separation of the axes or dimensions of differentiation.

Nonetheless, critics viewed this approach as lacking both an adequate theoretical rationale and sufficient empirical utility (Duncan, 1955; Hawley and Duncan, 1957; Van Arsdol et al., 1958). In their view, no clear theoretical relationship was specified between the basic concepts of social economic rank and ethnicity and the particular census tract variables used in constructing the index. Likewise, there was no particular advantage in using these social area indices instead of individual census measures which might produce considerably better results. These critiques implied that the indices were nothing more than arbitrary groupings of variables without a clear-cut rationale for their selection. In other words, the variables used to measure the three constructs were quite open to question. Social area analysis was yet a useful step in systematically measuring the multidimension of the modern urban community, and it helped to pave the way for more sophisticated and elaborate methods of urban research. In respect of the bias in variable selection, investigators applying social area analysis began seeking improvement in methodology. This awareness of methodological bias finally inspired researchers to adopt more advanced multi-variate statistical techniques. Social area analysis via factor analysis is the product of this academic movement. This 
approach, which is usually called factorial ecology, has advanced both theory and methodology. 
CHAPTER III

FACTORIAL ECOLOGY

"Factorial ecology" is the term used to characterize investigations applying factor analysis to ecological study. In this sense, it is an outgrowth and elaboration of the social area analysis approach. The term factorial ecology was introduced by Sweetser (Sweetser, 1965). The multivariate statistical technique of factor analysis, has been applied widely in various research projects, particularly in psychology. The primary objective of factor analysis is to reduce a large number of variables to a small number of underlying or latent factors, dimensions, components, or constructs. Briefly, it attempts to uncover the latent structural constructs. Such advantage is quite helpful to urban ecologists, for it can be employed to reveal those underlying factors, like the indices suggested by the social area analysis, which group and cluster the differences among the subareas of the city.

Those pioneering researches applying factor analysis or similar statistical techniques such as canonical correlation and cluster analysis, emerged in earlier 1930s. For example, Gosnell and Schmidt conducted research to analyze voting behavior in Chicago (Gosnell and Schmidt, 1936). And 
Price included 15 variables to study the metropolitan centers in the United States (Price, 1942). However, factorial ecology in fact originated in the mid-1950s, when the Shevsky-Bell scheme of metropolitan differentiation was proposed (Shevsky and Bell, 1955; Bell, 1955). With the rapid expansion of computing facilities which greatly stimulated interest in the factorial approach, sociologists suggested that the use of more variables detailing the socio-economic characteristics of census tract populations constitutes a logical expansion of social area analysis (Rees, 1970). Through the more sophisticated methods of factor analysis, the more fundamental patterns of variation in the data can be isolated, whether or not they conform to the main dimensions of social area analysis.

\section{EMPIRICAL FINDINGS OF UNDERLYING FACTORS} DIFFERENTIATING U.S. CITIES

There have been numerous major studies of single cities based on factorial ecology in the United states (Smith, 1973). Initially, the focus of factorial ecology was to validate and test the three basic constructs of social area analysis. The major empirical test of the three constructs which Shevky and Bell had hypothesized was conducted by Van Arsdol et al (Van Arsdol et. al., 1958). They carried out several factor analyses for ten metropolitan cities in the United states. These cities were not, like their previous studies, merely limited to 
California cities. Among them, the cases of Minneapolis and Seattle best demonstrated the empirical application of factorial ecology. Similar to Shevsky and Bell's model, they also found three main factors, i.e., social rank, urbanization, and segregation. Social rank was composed of occupation and education. Three variables--fertility, women in the labor force, and single-family dwelling units-constituted the second underlying factor which was labeled as urbanization. Segregation is defined by the percentage of negroes residing in the census tracts. In general, the factor analyses for Minneapolis and seattle provided empirical evidence supporting the validity of the model of social area analysis. The correlations in both cities are comparatively small between social rank and urbanization, and between urbanization and segregation. However, the correlation between social rank and segregation is quite strong but negative. ${ }^{3}$ It indicates that the social rank of the given census tract is negatively associated with its degree of segregation.

Factorial ecology gradually became popular and mature during the 1960s, and it increasingly departed from social area analysis. Among other things, two important differences could be identified. First, more variables are

${ }^{3}$ In that study, Van Arsdol et al. did not employ the conventional orthogonal method for factor rotation. Instead, an oblique rotation method was applied. Consequently, the statistical dependence among the factors could be described. 
found in factorial ecology than in the social area analysis. Because the identification of underlying latent factors is guided by the empirical results from the factor analysis, instead of by theoretical formulation before conducting the empirical study. That is, the factors underlying the differences between subareas of the city are uncovered by including as many variables as possible or available, and the investigator does not presume certain latent constructs. Second, factorial analysis pays more attention to the spatial patterning of derived latent factors. That is, the underlying factors derived from the factor analysis are deliberately explored with reference to their spatial patterning.

Rees's study of Chicago is one of the best illustrations of factor analysis of the American city (Rees, 1970). He compiled data based on 57 socioeconomic and demographic variables for 222 subareas of the Chicago SMSA, and performed a factor analysis. The first factor represented socioeconomic status which was measured by occupation, education, and income. The second factor dealt with stages in the life cycle, and was based on family size, age, and housing type. The third factor was comprised of race and resources. Race was measured by blacks percentage in a census tract, and resources the proportion of the total census tract population in low-status employment, with low incomes, and living in substandard housing. These three 
factors accounted for 45.1 percent of the variance in the original 57 variables.

Besides the Chicago study, factorial ecologies had also been conducted in the other major American cities, such as Boston, Buffalo, Indianapolis, Kansas city, Los Angeles, Newark, Providence, Seattle, Milwaukee, Minneapolis, San Francisco, Spokane, Sycrause, and Toledo. 4 Generally, consistent conclusions have been reached in these studies. The underlying factors revealed in these cities were quite similar, although the factors to be extracted are statistically sensitive to the inclusion and coverage of the input variables.

In summary, Rees' study of Chicago and many other studies of American cities (Berry, 1971; Berry and Kasarda, 1977; Hamm, 1982; Janson, 1980; and Timms, 1971), basically support that Shevsky and Bell's three social area indices are the essentially underlying constructs of the social differentiation in the cities. In other words, the empirical results inductively derived from the factor analysis of large sets of socio-economic variables generally justify the multi-dimensional model of social area analysis. However, investigators employing factor analysis are not merely satisfied with identifying and uncovering the latent

${ }^{4}$ Please see Hamm (1982) for detailed discussion and comparison of the empirical findings conducted in factorial ecology. In that article, Hamm also listed the dimensions of underlying factors in specific studies. 
factors. On the contrary, they suggest that there are certain associations between these socio-economic latent constructs and the spatial patterning. Accordingly, many studies attempt to examine the spatial patterns in the distribution of these socio-economic constructs.

\section{SPATIAL DISTRIBUTION OF UNDERLYING FACTORS}

As above-mentioned, one distinctive feature of factorial ecology from the social area analysis, is that once the underlying factors differentiating the city structure have been uncovered and extracted, the investigators, in turn, tend to be interested in the spatial distribution of these latent socioeconomic components. The examination of the spatial patterning of the latent constructs is usually generated by mapping the factor scores $^{5}$ on the city maps in relation to the classical ecological models discussed in a previous chapter. To a large extent, such study has often been focused on the comparison of zonal against the sectoral models of spatial

${ }^{5}$ In factor analysis, the latent factor can be assumed as a function of the linear combination of its correspondingly constituent variables. In terms of the linear function, the factor loadings of the correspondingly constituent variables are considered as the weighted coefficients, and the expected or estimated values of this linear function are the factor scores, which represent the measures of latent and dependent factors. Usually, in the process of calculating factor scores, the estimation is based on standardized variables. For more detailed discussion of the factor analysis, please refer to Harman (1960). 
distribution. That is, two competing models--concentric zone and sector models--are believed to be the expected spatial patterns of the distribution of the socio-economic latent factors underling the differentiation of the city structure. 6 Analysis of variance is the statistical technique most often used to empirically examine and validate the two spatial distribution models, i.e., zonal versus sectoral. However, the spatial patterning of the distribution of the socio-economic latent factors can also be examined in terms of other multi-variate methods, such as multiple regression with dummy variables and canonical correlation.

one of the earliest studies attempting to examine the spatial patterns of the latent factors was the research for four American cities of Akron, Dayton, Indianapolis, and Syracuse (Anderson and Egeland, 1961). The objective of this study was to apply the technique of the analysis of variance (ANOVA) to determine the role of zonal and sectoral variation in the spatial patterning of the underlying constructs of social rank and family status. Specifically, ANOVA was used to test two measurements (social rank and family status or urbanization) by zones and by sectors. With respect to the operationalization of the zonal and

${ }^{6}$ Harris and Ullman's multi-nuclei model has been examined by some studies. For example, Salins (1970) studied the household location patterns and found that the ethnicity dimension clustered in a multiple nuclei model. 
sectoral model, sectors were defined geometrically and zones were determined by a series of circles concentric to the city center.

The principal finding of Anderson and Egeland was that urbanization, or family status, varies primarily concentrically or by distance from the center of the city, while prestige value, or social rank, varies primarily among sectors with very little distance variation (Anderson and Egeland, 1961: 398). ${ }^{7}$ In other words, the results for the social rank dimension would support Hoyt's sector hypothesis, and the patterning of the urbanization dimension would be inclined to favor Burgess's concentric zone model.

Similar empirical findings have also been found for Chicago (Rees 1970) and Toronto in Canada (Murdie, 1969). Some conclusive statements can be summarized for the studies of the spatial distribution of the latent dimensions differentiating American city structure. First, the socioeconomic status factor, such as social rank or prestige, tends to vary sectorial. The family-status factor or the urbanization dimension often tends to be distributed according to the zonal model rather than the sectorial model. Specifically, the zones toward the city center are frequently occupied by small families, single-person families, and younger- or older-head-households. Herbert

${ }^{7}$ Moderate interaction effects between sector and zones is observed for family status. 
Gans' compositional theory of the population composition of the city can be recalled to explain. According to Gans' observation, the characteristics of the residents in the city vary distinctively across the city boundaries. In the inner subareas of the city, Gans had seen a mix of cosmopolitan people, including the single, professional, and other disadvantaged residents. On the other hand, people of the middle-class tend to live farther from the city center. At any rate, the clustering or grouping of residents with similar characteristics in terms of either the zonal or the sectorial process creates a picture of a so-called "urban mosaic", where each segment of the city is occupied by a cluster of residents who are homogeneously integrated within the segment and are heterogeneously differentiated from others across the segments.

While the analysis of the spatial patterning of the residential differentiation in terms of the distribution of the socio-economic latent dimensions has provided insightful observation and interpretation of the picture of an urban mosaic, it still involves certain methodological and theoretical limitations. For example, the problem and interpretation of the interaction effect in ANOVA has not been satisfactorily handled. That is, the number of analytical units and the classification of the zonal and sectorial segments, will sensitively influence the statistical significance of the main effects and interaction 
effects in the analysis of variance. The problem of classification of zones and sectors, in turn, is related to a debate concerning an ecological conception of distance. From the view point of classical ecology, the concept of distance or space is defined by the notion of time-cost, instead of a geometrical measurement. As a result, some researchers have argued that the measurement of zones and sectors in terms of geometrical or geographical distance may not capture the real ecological distance underlying human activities. Nevertheless, the concept of social distance and ecological distance is usually difficult to be operationalized in empirical studies.

\section{COMPARATIVE AND DEVELOPMENTAL FACTORIAL ECOLOGY}

Through the discussion of the literature in factorial ecology in last section, it can be observed that factorial ecology, while it has advanced in its methodology, still operates under the tradition of social area analysis. That is, the Shevsky-Bell scheme of three underlying dimensions-social rank, family status, and ethnicity--dominates the analysis of the latent components in American cities. Beginning in the 1960s, urban sociologists have been increasingly interested in the validity of this model in application to non-American cities.

The most striking difficulty in applying Shevsky-Bell scheme to non-American cities is in the third dimension of 
ethnicity. With the unique history of immigration in American cities, it is not surprising to observe the importance of an ethnicity dimension in differentiating the residential patterns. However, this does not hold true for other non-American cities. Moreover, lots of non-American cities are typically composed of a single ethnic group. Thus, the investigator must suspect and question the meaning and significance of ethnicity in differentiating residential patterns in the non-American cities. Insofar as the other two dimensions of Shevsky-Bell scheme are concerned, the existence of diverse histories of socioeconomic development and cultural heritage in other regions of the world, will undoubtedly exert certain effects on the intensity, strength, and direction of the social rank and family status dimensions in determining the differentiation of spatial patterning. A quite different scheme of spatial differentiation in non-American cities can be expected.

For instance, Dennis McElrath applied the Shevsky-Bell scheme in a study of Rome (McElrath, 1962). No measure of ethnic segregation was available, as a result, the finding would not support the dimension of ethnicity. Nonetheless, the other two dimensions, social rank and urbanization, appeared in the case of Rome. An important finding observed was the degree of urbanization and industrialization is substantially higher in American cities than in Rome. Thus, the emphasis on the urbanization dimension in 
differentiating residential patterning was found to be more important in American cities. In a study of Sunderland, an analysis of thirty variables resulted in a first component which could be interpreted as associated with social class (Robson, 1969: 159-67). The second component was a measure of housing conditions. Neither family status nor ethnicity emerged in this study.

By and large, those case studies conducted in western societies ${ }^{8}$ have produced a conclusion that conforms closely to the standard North American patterns. The deviance derived from empirical findings, however, suggests that a valid factorial ecological theory and model will need to be related to ideas on the process of modernization and the history of social changes. This is particularly important for the non-Western societies, for they present a completely different process and stage of modernization. A research question can be stated as: what is the spatial patterning of the underlying dimensions of differentiation in cities in the developing societies?

An important comparative study of factorial ecology was launched by J. L. Abu-Lughod on Cairo (Abu-Lughod, 1969). Thirteen variables were employed. The first factor extracted was identified as representing "style of life,"

${ }^{8}$ Hamm (1982) had presented a list of factorial ecology studies in Europe, Canada, Australia, and New Zealand. From this list, the reader can easily determine their similarity with the standard patterns in American cities. 
for its constituent variables highly reflect economic aspects of a life style. The second factor is interpreted as representing a "male-dominance," and the third, as "social disorganization." One of the most significant findings in this study is that certain variables of family status had a close association with the variables of social rank (Abu-Lughod, 1969: 207). This is a particularly strange finding deviant from that in American cities. In American cities, the correlation between social rank and ethnic segregation is very strong, but little association could be observed between social rank and urbanization, or family status. The explanation of the unique association between family status and social rank in cairo, then, should be traced back to its distinctive cultural and social organization, for the extended family tradition is a typical social and cultural devise in Egypt. In sum, this study implies an important suggestion that conventional Western variables may be of little use and meaning, unless the cultural variation and the process of social change have been taken into consideration.

Another unique feature in studying the factorial ecology of non-Western cities is to find out the collapse of traditional patterns and the emergence of new spatial arrangements. With the advent of industrialization, the concomitant development of the transport facilities, and the growth of commerce, many cities in the developing societies 
moved away from the traditional model into a modern pattern. Timms provided a summary table for a topology of cities (Timms, 1971: 146, table 4.4). He suggested that at least six types of cities could be distinguished in the world: modern city, feudal city, colonial city, immigrant city, pre-industrial city, and industrializing city. Within each of the six types, the underlying constructs that differentiate the residential area and spatial pattern are not only different but also present diverse mechanisms in forming the differentiation dimensions.

From the view point of evolution, there are some common characteristics of economic and social changes among various societies at different stages along the evolutionary continuum. Nonetheless, these societies are not uniform, and they diversify in cultural tradition and politicoeconomic structures within which social change takes place. Moreover, London and Flanagan observed that "The accumulated evidence indicates that economic and technological factors are the independent variables which tend to produce ecological similarities, while culturally unique factors are the independent variables which tend to foster ecological difference" (London and Flanagan, 1976: 59). Accordingly, while there may exist similarities of the spatial patterning of the differentiation between non-Western cities and Western cities due to the diffusion of economic development 
and modernization, certain differences still could be found among them, at least in their ecological morphology.

Both factorial ecology and social area analysis have been criticized for relying almost exclusively on the data from census reports. Some unavailability of certain census reports will also cause the omission of certain indices or dimensions in the different studies conducted in different countries. Consequently, some of the important conditions of human existence that may be spatially differentiated are not included in these approaches. This is particularly true for conducting the factorial ecology study in the developing societies, for both the quantitative and qualitative data sets are very difficult to be found and collected. Some social scientists suggest that researchers apply different data collecting methods and combine them with census reports to resolve the limitation of comparability (Smith, 1973). Nonetheless, this limitation remains unsolved for most nonWestern countries, because statistics are also underdeveloped in these areas. This limitation may be responsible for the lack of comparative factorial ecology studies in these areas, especially in Asian countries. 9

On the whole, factorial ecology is the ecological study of urban areas through factor analysis. From a set of

${ }^{9}$ While there are some comparative studies conducted for Latin America and Africa, or even India, there is little work that is designed for analyzing the factorial ecology in Asian countries. 
socio-economic, demographic, and other variables, researchers found underlying factors differentiating the spatial pattern of the city. For example, economic status, environment, health, education, social disorganization, participation and equality, family composition and life cycle, are all important potential variables from which certain latent and underlying factors differentiating the spatial pattern of the urban community are expected to be extracted.

Most factorial ecology studies were conducted in 1960 s and 1970s. And the typical target is to uncover the latent dimensions underlying the residential differentiation of the city. Recently, the technique of factor analysis has been fully developed, accompanied by the sophistication and advancement of computer-assisted methodology (Janson, 1980). But, until recently, the factorial approach has not always been utilized to its full potential in social and urban ecology. According to Berry and Kasarda, the classical ecological approach to understanding residential structure had three major goals: first, to apply concepts derived from plant ecology, such as competition, invasion, and succession, to the analysis of urban neighborhoods; second, to provide detailed descriptions of natural areas or social area within cities; and third, to investigate the relationships between these social areas and various kinds of social pathology (Berry and Kasarda, 1977: 5-6). Some 
useful and practical applications of factorial ecology have been extended to other fields both inside and outside sociology. Among them, crime and related issues and the extension of medical service best exemplify such application. ${ }^{10}$

This and previous chapters have briefly described and discussed the theories and models in extant literature that attempt to explain the spacial patterns of human social activities in the urban community. Basically, investigators suggest that human social activities in the urban community have been dominated by certain underlying constructs, and these constructs are the criteria for the differentiation of the city structure. Furthermore, the differential

constructs are expected to present specific patterns of

${ }^{10}$ In criminological studies, one dominant paradigm is the differential association theory. This theory assumes that criminal behavior is the product of a socialization process whereby adolescents become delinquent because of their interaction with criminal groups. This notion of deviant subcultures within cities implies the influence of social context upon individual criminal behavior. That is, the environment of residence would be an important factor in accounting individual criminal behavior. Here, conventional factorial ecology is successfully adopted to examine the differential association model. For example, C. F. Schmid had undertaken an analysis of crime in seattle in terms of factorial approach (Schmid, 1960). Schmid attributed certain crime variables to the relation with social area constructs, such as social rank and family status. He found that most of the crime indicators were negatively related to social rank and family status, and positively related to the ethnic segregation. Recently, factorial ecology has also been applied to the study of place of crime and its association with the routine activities (for example, Sherman et al., 1989), the prevention of crime (Felson, 1987), and the association between crime and religion (Groves et al., 1987). 
distribution along the spatial dimension. While the empirical findings in American cities show a consistent trend, the situation in the non-American cities, especially in non-Western cities, still remains unclear. It is this objective that this study attempts to develop by employing a Taiwanese city to supplement the factorial ecology in Asian cities. In the next chapter, an operational design describing the concrete procedure in conducting a factorial ecology study in Taiwan will be described. In addition, a brief history of ecological structure and social development in Taiwan will be presented. 


\section{CHAPTER IV}

\section{SPATIAL DISTRIBUTION OF THE RESIDENTIAL AREA: AN ANALYTICAL FRAMEWORK}

From the preceding review, it is clear that the urban community is neither an undifferentiated mass nor a haphazard collection of buildings and people. Rather, in the course of differentiation, populations with similar characteristics tend to cluster together and come to characterize their areas. In Park's view, every sector and quarter of the city takes on something of the character and qualities of its inhabitants in the course of time. Each part of the city is inevitably stained with the peculiar sentiments of its population. The effect of this is to convert to a mere geographical expression into a neighborhood, that is, a locality with sentiments, traditions, and a history of its own (Park, 1952).

The residential differentiation of an urban population takes place in terms of many attributes and in many ways. Nearly any criterion that can be applied for differentiating between individuals and groups may become the basis for their physical separation. The process of separation may be accomplished through force, through a variety of sanctions, through voluntary aggregation designed as a defense against unfamiliar ideas or customs or as an escape from persecution 
and discrimination, and through a selection by market forces.

Residential differentiation and the resulting segregation of populations serve many purposes. Physical isolation symbolizes social isolation, and decreases the chances of undesirable and potentially embarrassing contact. Furthermore, segregation may provide a means of group support in the face of a hostile environment, and it may even lead to administrative efficiency. As Wirth observed, the physical isolation of differing populations seems an inevitable concomitant of 'urbanism as a way of life.'

CONCEPTUAL FRAMEWORK: THE APPLICATION OF FACTOR ANALYSIS

To understand the spatial patterning of residential differentiation, each of the diverse differences in some way should be taken into account. As discussed in preceding chapters, various approaches and theoretical perspectives have been developed and adopted by urban sociologists to describe as well as to analyze the spatial differentiation process in the urban community. Under the tradition of the natural-area approach, three models were reviewed to map the metropolitan anatomy: concentric zone theory, sector theory and multiple-nuclei theory. Later on, the concern shifted to the social aspect of the urban community. Social area analysis, which is based on key variables that deliberately characterize the significant differences among subareas in 
the city, is a good approach to analyze spatial patterning. However, the best and most popular tool for conducting such studies is factor analysis.

Basically, factor analysis has several mathematic advantages in assessing the validity and meaning of a set of variables. Harman suggests that the principal concern of factor analysis is the resolution of a set of variables linearly in terms of a small number of categories or "factors". This resolution can be accomplished by the analysis of the correlations among the variables. A satisfactory solution will yield factors which convey all the essential information of the original set of variables. Thus, the chief target is to obtain scientific parsimony or economy of description (Harman, 1976). Moreover, factor analysis provides a powerful technique for unravelling the connection between manifest variables and the underlying constructs which they represent. Scholars believed that there were some unobserved factors underlying the spatial patterning of the urban community. With factor analysis, urban sociologists can, therefore, reveal many significant latent structures.

The advantage of factor analysis lies in the fact that it is possible to account for the manifold variation in neighborhood characteristics in terms of a much smaller number of underlying constructs. In mathematical terminology, the aim of the analysis may be seen as the 
reduction of the original $n$-sub-area by s-variable matrix to an $n$-sub-area by m-factor matrix, in which $m$, the number of significant factors, is considerably less than $s$. The criteria of significance resides in both the statistical aspects and substantive properties of the factors, in accounting for a certain proportion of variance, and in their theoretical connections. ${ }^{11}$

The findings of the factorial ecological studies in the U. S. and Western European countries are similar. However, in non-Western societies, where the urbanization process is proceeding dramatically, there are few empirical studies. Thus, Kaohsiung city, the second largest city and the most important industrial center in Taiwan, is employed to investigate the spatial patterning of residential differentiation in a non-Western setting. Taiwan has an excellent household registration system, and the demographic statistical system is quite reliable; hence there are abundant empirical data available for this kind of study. In addition, Kaohsiung city is the most important commercial and industrial center in Taiwan, and its population exceeded one million in 1980. The later part of this chapter will give a brief depiction about the ecological structure and

${ }^{11}$ For a detailed introduction and discussion of conducting factorial ecology, see Johnston (1976). In this single-piece work, the author had demonstrated the specific steps and basic notions of factor analysis. 
social development of Taiwan in general and Kaohsiung city in particular.

Kaohsiung city provides an appropriate case study for factorial ecology in non-Western societies. Accordingly, factor ecology was employed by this study to uncover the latent structure which underlies the differentiation and grouping of social differences of the urban residents. Specifically, there were two primary goals in this study. First, assuming the existence of latent structure, factorial ecology was employed to uncover any underlying forces that differentiate the residential patterning of Kaohsiung city. second, attention will then turn to the spatial distribution of the underlying dimensions that differentiate residential patterns in Kaohsiung city. Therefore, in this study, the first objective is to conduct a factor analysis, by including as many areal attributes as possible, to uncover the underlying constructs that differentiate the social ecology in Kaohsiung city. Once the latent constructs have been revealed, the focus of this study will turn to examine the spatial distribution of these latent constructs. That is, the purpose is to suggest appropriate ecological model for these latent dimensions.

DATA SOURCE AND VARIABLES

The unit of analysis used in this study is the "LI". LI is an administrative subunit of the township, and it is 
compared to the census tract in America. Additionally, LI also takes the role of socioeconomic and marketing functions in Taiwanese society. In fact, it is legitimate to refer to the LI in Taiwanese society as a so-called natural area. There are 383 LIs in Kaohsiung City. The originally plan was to include all of them in the analysis. But, due to the limit of data collection and data source availability, 43 new LIs have missing values in certain areas. Only 340 LIs will be included in this factor analysis in order to avoid the potential statistical problem of estimating parameters based on missing values. ${ }^{12}$

Because there is no previous study regarding the human ecology and urban spatial patterning in Taiwan, the exploratory factor analysis was adopted in this study. In addition, ecological and socioeconomic attributes were collected as many as possible. Included in the model are many socioeconomic variables which have been found significant in either Western or non-Western society. Accordingly, those characteristics, including population structure, marriage, female reproduction pattern, education, labor force, crime, infrastructure and land use, would all be encompassed in this study for factor analysis.

${ }^{12}$ The administrative system was dramatically changed around 1980. Unfortunately, the filing system of public documents could not be updated by and shifted to the new authority. As a result, information about the crime, public utility, and land value was unavailable for some subareas. 
Part of the data employed in this factor analysis was collected in 1981 by the Kaohsiung City Government, and the bulk was published in statistic Summary of Kaohsiung Municipality, 1982. The other part of the data was collected from 1980 census reports, and provided by the Kaohsiung City Government. In the exploratory analysis, it included demographic variables (such as age structure, family composition, and migration), economic variables (for example, the rates of employed and economically active persons in the population, occupational activities, infrastructure, and retail value), crime records, and other available socio-demographic variables. But this study did not include those characteristics related to ethnicity, because serious ethnic segregation in residence had never been observed and it is impossible to collect information about the resident's ethnic characteristics. ${ }^{13}$

${ }^{13}$ There are four major ethnic groups in Taiwan: Chinese Mainlanders, Fukienese, Hakkas, and aboriginal. These four ethnic groups differ substantially in many respects, including ideology, language, demographic composition, family structure, social relation pattern, and cultural heritage. Historically, the Hakka people have been geographically separated from the largest majority, Fukienese, and they usually reside in relatively poor, backward, and mountain areas. It is also the case of the aboriginal. Chinese Mainlanders, consisting of people immigrated from Mainland China mainly after the china civil War (1946-49), differ from native Taiwanese primarily in their occupational structure and demographic composition. A large proportion of Mainlanders are retired soldiers (veterans), and the remaining are employees in government and administrative sectors. Geographically, chinese Mainlanders always concentrate in major cities; Hakkas and aboriginal reside in mountain as well as rural areas; and Taiwanese or Fukienese largely distribute in urban and plain 
The variables employed in the present study are listed and defined in Table I. On the whole, there are nine sets of characteristics which contain forty-nine variables. ${ }^{14}$ The nine sets of characteristics are: demographic structure, educational attainment, marriage statistics, migration, occupational structure, employment statistics of the labor force, poverty, crime statistics, and infrastructure.

A BRIEF DEPICTION OF THE ECOLOGICAL STRUCTURE IN KAOHSIUNG

Taiwan is the largest island off the South-East coast of the China mainland. Since 1949, Taiwan has been the only province remaining under the Nationalists' control. To some extent, Taiwan could be said to be an independent country, rather than just a part of Great China. Historically, Taiwan is developing relatively homogeneously, in terms of both societal structure and ecological morphology .

areas. Consequently, the urban population fundamentally compose of Chinese Mainlanders and Fukienese. However, the public policy in Taiwan is strongly against ethnic segregation and separation, and, in fact, there has never been seen serious ethnic conflict during last several decades. While the ethnic factor still operate at some extent, it has been questioned for inclusion into public sphere in Taiwan. Moreover, the only one source of ethnic data had been collected in 1966, and, since then, no further data pertaining to ethnicity are available.

${ }^{14}$ In order to avoid the problem of multi-collinearity-that is, a given variable is the linear combination of some of other variables included in the model--it did not completely include all the variables into analysis. 
TABLE I

DEFINITIONS OF VARIABLES

VARIABLE NAMES DEFINITION

1. POPULATION CHARACTERISTICS

Population Density

Number of residents per square $\mathrm{kilometer}$

Crude Birth Rate

Number of new born children per thousand people in a year

Crude Death Rate

Number of deaths per thousand people

$\%$ of Population Aged $0-4$

Ratio of population aged $0-4$ to

total population

$\%$ of Population Aged 15 and over

Ratio of population aged 15 and over to total population

\% Population Aged 15-64

$\%$ of old and sick

Ratio of population aged 15-64 to total population

Ratio of old and sick population to total population

2. EDUCATION

\% of University or College Graduates

$\%$ of $\mathrm{High}$ School Graduates

Rat io of population completing college and above to total population

Ratio of population completing only high-school education to total population

\% of Primary School Graduates

Ratio of population completing only primary-school education to total population

$\%$ of Pop not in School Aged 6-15

Ratio of population, aged 6-15, not in school to total population

3. MARRIAGE

$\%$ of Family Households

$\%$ of single Households

$\%$ of single Pop Aged 15 \& over

$\%$ of Female Single Pop Aged over 15

Percentage of Family-households among total households

Percentage of single-households among total households

Number of single population aged 15 \& over per thousand population

Number of female single population aged over 15 per thousand population 
TABLE I

DEFINITIONS OF VARIABLES

(continued)

3. MARRIAGE (Cont inued)

$\%$ of Widows Aged over 15

Number of widows aged over 15 per thousand population

$\%$ of Divorced Pop Aged 15-64

Number of divorced population aged 15-64 per thousand population

4. MIGRATION

\author{
Net Migration Rate \\ Inter Precinct \\ Net Migration \\ Rate \\ $\%$ of Non-native \\ Residents
}

5. OCCUPATION

\% Government Employees

$\%$ of Professional \& Technical Workers

$\%$ of Service Workers

$\%$ of Self Employed

\% of Private Employees

$\%$ of Agricultural \& Related Workers

$\%$ of Unpaid Family Members

\% of Employers

$\%$ of Administrative, Managerial Workers

$\%$ of Clerical \& Related Workers

$\%$ of Sales Workers

$\%$ of Production \& Related Workers

$\%$ of Housekeepers

$\%$ of Female Housekeepers Proportion of female housekeepers
Net inter-precinct migration rate per thousand population

Net migration rate per thousand population

Rat io of non-native Kaohsiung residents to total population

Proportion of government employees among all employees

Proportion of professional \& technical workers anong all employees

Proportion of service workers among all employees

Proportion of self employed among all employees

Proportion of private employees among all employees

Proportion of Agricultural \& related workers among all labor force

Proportion of unpaid family members among all labor force

Proportion of employers in private bus iness among all labor force

Proportion of administrative \& managerial workers among all labor force

Proportion of clerical \& related workers among all labor force

Proportion of sales workers among all labor force

Proportion of production involved \& related workers among all labor force

Proportion of housekeepers among all labor force among all labor force 
TABLE I

DEFINITIONS OF VARIABLES

(continued)

6. EMPLOYMENT

Employment Rate
Employment Rate of
Males
Unemployment Rate of
Economic Active
\% of Male Economic
Active Pop.
$\%$ of Female Economic
Act ive Pop.
Econonically
Inactive Rate

Number of employed population per thousand population

Number of male employed population per thousand population

Number of unemployed of economically active population per thousand population

Male economically active population anong all male labor force

Female economically active population among all female labor force

Number of economically inactive population to total population

7. CRIME

Crime Rate
Sedition Rate
Property Crime
Rate
Prostitution
Crime Rate
Violent Crime
Rate
Other Crime
Rate

Number of all criminal cases per thousand population in one year

Number of sedition crimes per thousand population in one year

Number of crimes against property per thousand population in one year

Number of prostitution crimes per thousand population in one year

Number of violent $\mathrm{cr}$ imes per thousand population in one year

Number of crimes not included in the above four crimes per thousand population in one year

8. POVERTY
$\%$ of Poverty Household

Ratio of households in poverty to total household

\section{INFRASTRUCTURE}

Amount of Public Infrastructure

Total Land Value

Amount of public infrastructures with in administrative boundary

The total value of land 
This study using factorial ecology is a typical aggregate or area analysis. One serious difficulty associated with the area study is the selection of the unit of analysis or contextual boundary. The investigator usually defines the spatial or geographic units where the respondents being studied reside as the most relevant ecological contexts of individual social behavior. There exit several problems that need to be acknowledged with this approach. Among other things, it is difficult to define geographical boundaries that correspond to natural areas. The selection of a geographical or spatial boundary most relevant to the ecology of individual social behavior under investigation is a problem. Non-natural geographical boundaries, such as administrative divisions, may change over time due to political consideration, and, consequently, may not perfectly reflect the ecological meaning of a social area as the arena of individual daily life. The geographical boundary sometimes does not really reflect the spatial dimension of social activities and networks adopted by those people residing within it. These problems do hold true for this study. Therefore, it is necessary to examine the unit of analysis in this study.

\section{Administrative and Ecological Hierarchy}

In Taiwan, the existing administrative division system provides useful and valuable geographical boundaries, with respect to those shortcomings of area analysis mentioned 
above. According to Skinner's theory of market town, market towns serve as the focus of most people's extra-village activities in Chinese society (Skinner, 1964). Empirical study of the market town in Taiwan (Crissman, 1972) has demonstrated that the current administrative division boundaries correspond to the natural market area, religious circle, and social network that most relate to residents's social life. That is, the existing administrative division classification system in Taiwan can be employed to reflect the spatial patterning of social as well as economic activities conducted by the people living within the given context. In other words, the administrative hierarchical system can be said to represent the ecological structure in Taiwan.

There are various administrative division hierarchies. Taiwan island as a whole is a province under the control of Nationalist government, ${ }^{15}$ and it consists of 21 counties and cities supervised by Taiwan Province government (see Figure 1). The next administrative level under the Province division is township. Township units include 361 urban precincts, small cities, urban townships, rural townships, and aboriginal townships. In general, a county is a relatively large administrative unit in Taiwan, for it usually contains 20 to 35 townships--including both urban

${ }^{15}$ This political territory is the well-known "ChineseTaipei" government, in comparison to Mainland China's government of "China-Beijing." 
and rural as well as, sometimes, aboriginal areas. on the contrary, township provides a homogeneous and autonomous ecological context. Residents within the given township could enact social, political, economic, and cultural activities without leaving the boundary. However, the real arena of social life is another lower level of administrative division--LI. On average, the population size of LI is about one to four thousands. Most of people's daily lives are performed within this boundary, and the residents can fulfill almost all daily needs from within it. Thus, LI is the most important residential unit in Taiwan.

\section{Urbanization in Taiwan During Last Four Decades}

Administratively, the Taiwan Island is divided into five major cities and sixteen counties (see Figure 1). There are also another two municipal cities, Taipei and Kaohsiung. Taipei and Kaohsiung municipalities are, of course, the transportation, commercial, and political centers of the island as a whole. Other smaller cities also have similar functions as industrial, economic, and political centers of their surrounding areas. Nonetheless, Taipei and Kaohsiung municipalities are more significant. Their population accounts for about twenty percent of the total population in Taiwan.

During the Japanese colonial period (1895-1945), there were seven municipalities. After 1930 they increased to nine. However, all of these municipalities, except Taipei, 
were not great metropolises at that time. Under the ching dynasty (before 1895), Taipei was only a commercial center of northern Taiwan. Since the Japanese had selected Taipei as the colonial capital after 1895, this city became a distinct political and economic center in Taiwan. significant developments were brought into this city by the Japanese, and Taipei appeared to function as the most important urban center on the island. Considering the agricultural economy of this colonial island, the other eight relatively small cities also differed significantly from the rural areas. The most impressive city with tremendous population growth was the Japanese designed and developed new harbor of Kaohsiung in the south. This city increased its inhabitants 3.6 times from 1920 to 1940 , and jumped from the seventh to the third largest city in Taiwan.

After World War II Taiwan received about 1.5 to 2 million mainland Chinese immigrants. Most of them resided in the major cities and their nearby areas. These Mainlanders substantially increased the urban population in Taiwan. The massive socioeconomic developments that occurred after 1950 also accelerated the pace of urbanization since most new industries were built up in the major cities and their surrounding areas. Among them, Kaohsiung city underwent a rapid urbanization process.

In 1920, the population in Kaohsiung city was only twenty-seven thousands. As the most important commercial, 


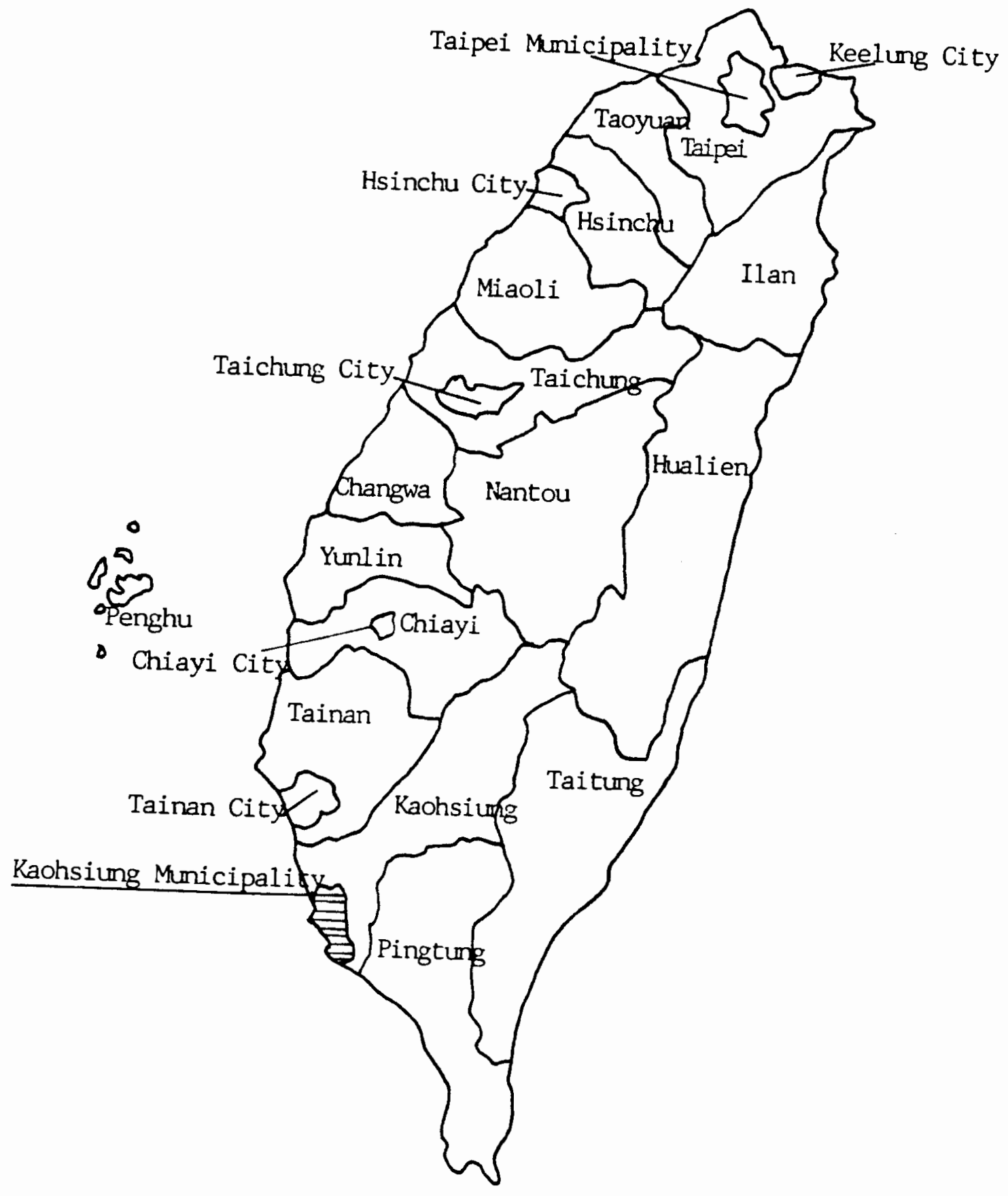

Figure 1. Administrative System in Taiwan. 
industrial, and military harbor city during sino-Japanese War, Kaohsiung city had received a substantial numbers of immigrants. At the time that the Nationalist government began to control Taiwan island, the population size of Kaohsiung city had exceeded one hundred thousand. Rapid and dramatic economic progress also appeared between 1950s to 1970s. Not only was Kaohsiung the most important commercial harbor in Taiwan during this period, also it was the industrial center that the Nationalist government attempted to invest in and develop as the so-called "Taiwan's Miracle." Another unique feature of the urbanization policy in Taiwan had affected Kaohsiung city's development also. In order to balance the population distribution across the island, Kaohsiung had been encouraged as the second urban center of Taiwan to attract the migrants from the southern part of the island. Subsequently, related policies and infrastructures had been massively developed and established for Kaohsiung's progress. With the advantages of being the largest seaport both in the south and in the whole island, Kaohsiung, therefore, was rapidly industrialized after 1950 . Moreover, two of the three most successful economic devices of "Free Exporting Zones" are located in Kaohsiung city, and both have attracted a significant number of workers and their families to live in this city. By 1980, the population size of this city had exceeded one million $(1,202,123$ in 1980$)$. 
On the whole, there are three significant functions Kaohsiung city has taken: commercial, industrial, and military. Kaohsiung city is the second largest commercial center (Taipei is the largest one), but is the largest seaport in the island for international trade. Hence, it is not difficult to imagine the vigorous and energetic business activities occurring in this city. In reality, a majority of the manufacturing and agricultural products of this island are exported from this seaport to other countries. Industrial production is another distinguished function that Kaohsiung city played. Most of the heavy industries in Taiwan are located in this single city, and, more important, as mentioned above, is the establishment of "Free Exporting zones." Basically, Taiwan is an economic country established on the basis of international trade. The success of Taiwan's international trade should be partly attributed to the successful performance of the establishment of "Free Exporting Zones." Several of the largest industrial establishments in Taiwan are located in Kaohsiung, such as China steel Corporation Plant, Integrated Steel Mill, Kaohsiung Shipyard, and China Petrochemical Industry--some of them are indeed the largest in the world. These industrial establishments and exporting zones have attracted thousands of business persons and workers, and they are, indeed, the symbol of commercialization and industrialization of the economic progress and success of 
Taiwan. This may also be a reason for the incredibly rapid urbanization in Kaohsiung city during last four decades.

with respect to the military mechanism, Kaohsiung city is one of the largest army and navy center in Taiwan. ${ }^{16}$ In fact, almost all of the military institutes are distributed within Kaohsiung city or nearby areas. The military mechanism not only creates a great number of military personnel, but also bring many related persons, for example, the workers for defense industries. In general, the military bases are easily identified, because they are located and concentrated in certain specific areas, especially at the northern and south-eastern part of Kaohsiung city.

Administratively, Kaohsiung is the municipality, equivalent to the province-level in Taiwan. It contains eleven precincts (please see Figure 2). LI is the third and smallest administrative division. There are 383 LIs in Kaohsiung city. As discussed above, LI is the real arena for its residents' daily social life, and, thus, it would be the appropriate target unit of analysis in this study.

Throughout this chapter, the analytical framework for the analysis in this research have been formulated, with a

${ }^{16}$ The long-lasting conflict between China and Taiwan makes it necessary for Taiwanese government to establish a powerful national force to survive. And the requirement for having a protective national defense system, unfortunately, asks this island to invest more than fifty percent of its national gross product in national defenses budget, and it creates half million military personnel. 
SEA

SEA

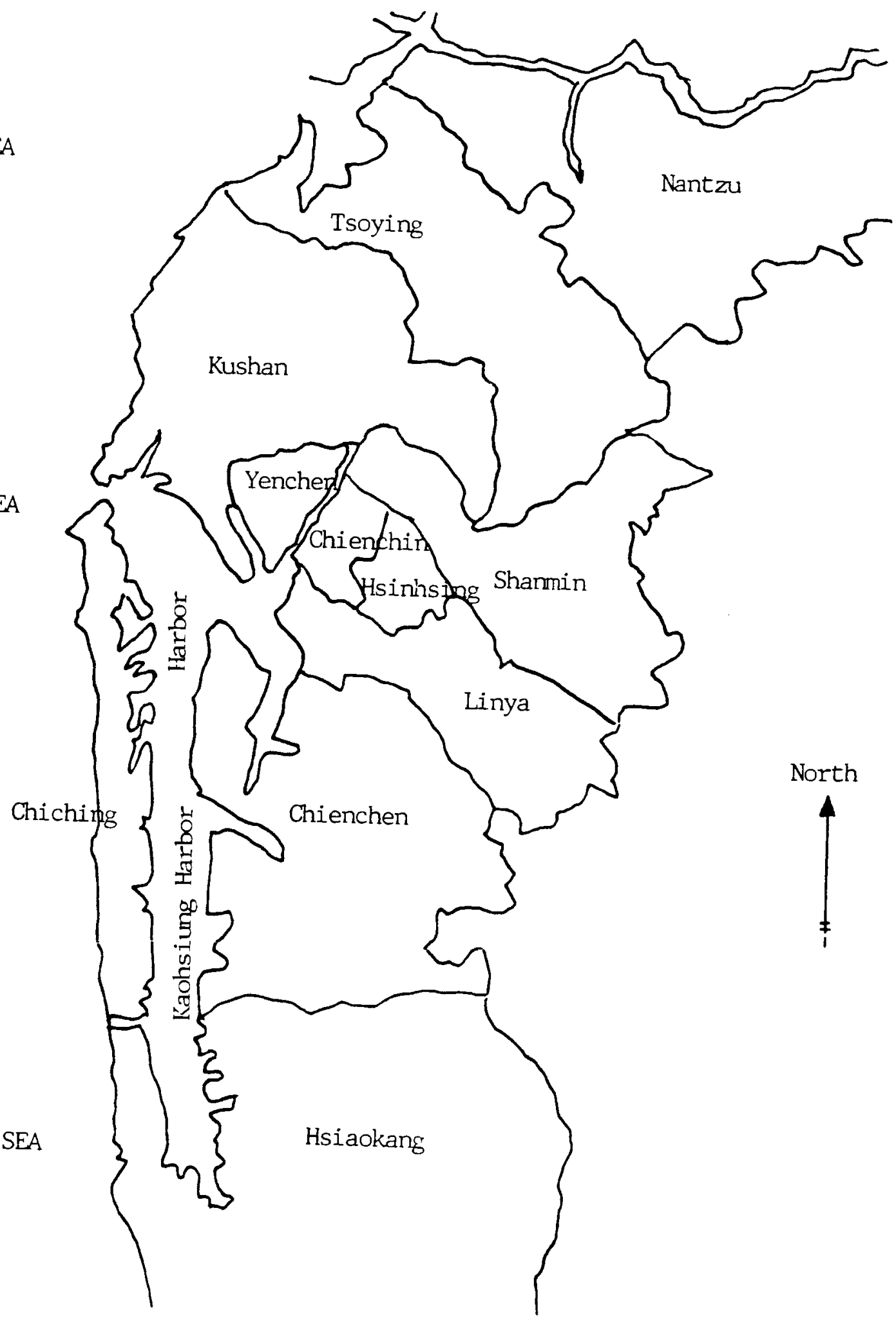

Figure 2. Administrative Classification of Kaohsiung City. 
brief description the urbanization and development history of Kaohsiung city. In the following chapter, the research results and findings to demonstrate the underlying dimensions that differentiate the socioeconomic structure in Kaohsiung city will be presented. An examination of the spatial distribution of these dimensions in terms of classical ecological models will be included. However, there was no study of the spatial and ecological model of Kaohsiung city. Therefore, it is necessary to arbitrary define some ecological models, particularly the concentric zones and sectors, to examine the spatial distribution of socio-economically latent constructs differentiating the Kaohsiung city. The definition and classification of ecological models of Kaohsiung city will be discussed and described in the next chapter. 


\section{CHAPTER V}

SPATIAL PATTERNING OF RESIDENTIAL DIFFERENTIATION IN KAOHSIUNG CITY, 1982

This chapter presents the empirical results and findings of this study. The specific objectives of this study are to uncover the socio-economic latent dimensions that underlie the differentiation of urban structure in Kaohsiung city. In addition, the interest focuses in the spatial distribution of these underlying dimensions, because there must exist certain spatial patterning, similar to classical ecological models in Western cities, dominating the spatial distribution of latent constructs in Kaohsiung city. In order to uncover the latent dimensions, factor analysis was applied to analyze forty-nine demographic, socioeconomic, crime, and other related variables. Results and findings of factor analysis will be described and discussed in detail in the first part of this chapter. The technique of analysis of variance, then, was employed to examine the spatial patterning of the underlying dimensions of the residential differentiation in Kaohsiung city. The second part of this chapter is devoted to discussing the results of ANOVA. 
FACTORS UNDERLYING RESIDENTIAL DIFFERENTIATION: RESULTS OF FACTOR ANALYSIS

Nine sets of characteristics, summing up to total forty nine variables, were included in the factor analysis. The units of analysis in data set number 340 . For the univariate statistics of the forty-nine variables in the model, appendix lists their means and standard deviations respectively. Initially, the raw scores of these variables were input in the factor analysis. With the correlation matrix used to conduct factor analysis, no significant multi-collinearity was observed among these forty-nine variables.

The method used to extract factors behind variables was conventional principle component analysis (PCA). Several methods could be employed as the criteria for determining the number of factors finally extracted. After comparing the results from various methods, the first seven factors were chosen. Figure 3 shows the scree plot of the eigen values. It is easy to observe the decreasing trend of eigen values in Figure 3. The cumulative eigen values of the first seven factors account for $56 \%$ of the variation.

These seven factors were then rotated using the normalized varimax method. The oblique method for rotating the factor loadings was not employed because the primary interest was not to examine the association among the factors, but rather in isolating the simplest structure. 


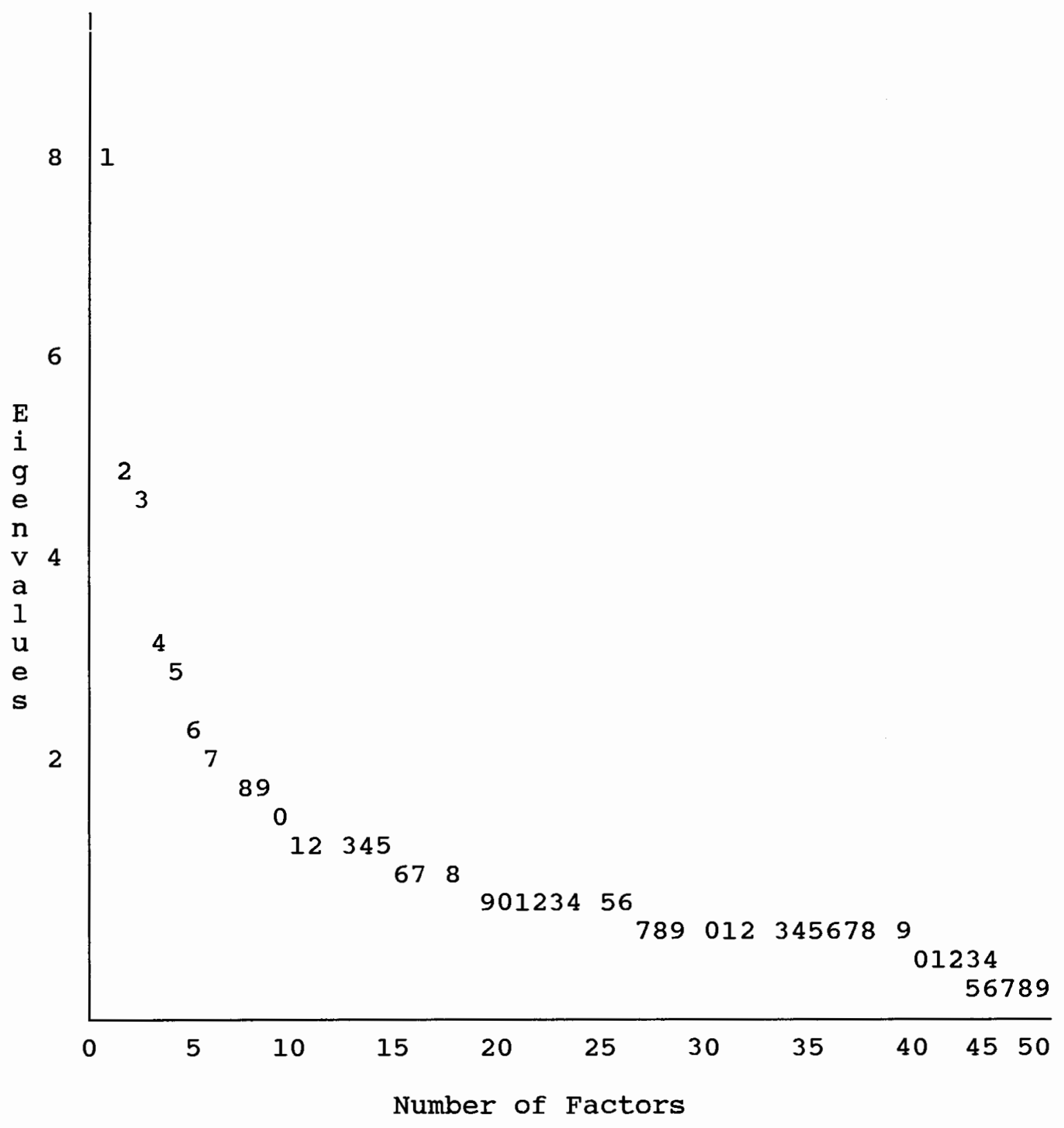

Figure 3. Scree Plot of Eigenvalues for Factor Analysis. 
Table II presents the factor loadings, communality, and eigen values for each variable on the rotated factors. The seven underlying factors differentiating the residential patterns of Kaohsiung city are professionalism, commercial activity, disadvantageous opportunity, vice, female labor participation, disability, and employment opportunity, ordered according to their amount of explained variance of the residential differentiation. The following will discuss and interpret the composition of these factors in detail. Sustenance activities dominate the distribution of population in geographic locations. In modern urban society, two key sustenance activities can be identified, professionalism and commercial activity. In fact, these two activities significantly distinguish the urban community from the rural community. The growth of professionalism was an integral part of the increasing complexity of the division of labor in modern society, and it is seen that the social differentiation of contemporary society is moving toward the development of professionalism. As for commercialization, it is almost unquestionable to accept its importance in contemporary social life. Both professionalism and commercial activity are found to be important in Kaohsiung City. In fact, these two dimensions are the most important in differentiating people's social life in Kaohsiung city.

The first factor, professionalism, is indicated by 
eleven variables: (1) percentage of government employees;

(2) percentage of high school graduates; (3) percentage of non-native residents; (4) percentage of university or college graduates; (5) percentage of professional and technical workers; with negative loadings for: (6) percentage of service workers; (7) percentage of selfemployed people; (8) crude birth rate; (9) percentage of private sector employees; (10) percentage of agricultural and related workers; and (11) percentage of people with only primary school education (see Table II).

Conventionally, the professionals are composed of persons in the Law, the Church, Medicine and the Armed Services. In Taiwan, the professionals tend to be government employees. They must attain a high level of education and pass a series of examinations in order to enter government service. Once hired, government employees usually migrate from one place to another because of job rotation or promotion. Consequently, many of Kaohsiung city's workers are not natives.

As mentioned in previous chapter, Kaohsiung has several huge military bases, both for army and navy. The bases attract thousands of people to Kaohsiung. Basically, both the soldiers and officials should attain at least high school education in Taiwan, and, in fact, most of them are 
college graduates from the military educational institutes. ${ }^{17}$ There is one distinct feature of the military personnel in Taiwan--a majority of them are chinese Mainlanders. These Mainlanders are immigrants from China after the China Civil War. Due to the status of immigrants, these Mainlander soldiers face particular difficulty in finding mates for marriage, for the sex ratio of the Mainlander immigrants is very high and Taiwanese natives tend to refuse to marry with these strangers. Consequently, many of these soldiers remain single throughout their whole life. This is one of the reasons the crude birth rate is negatively associated with the factor of professionalism. In addition, there are two large national enterprises in Kaohsiung: China Shipbuilding Corporation and China steel Corporation. ${ }^{18}$ They draw many "high-tech" professionals. of course, these high-techs should have high educational attainments, and the opposite--the percentage of graduates from only primary education--will be negatively associated with this factor. Nevertheless, it is also possible to recognize negative traits. For example, the proportion of the self-employed population, or percentage of population participating in service, agriculture, or related work

${ }^{17}$ One of the minimum requirement to be an official in military service is a degree of bachelor. All of the officials in China Army and China Navy are all graduates from Military University.

${ }^{18}$ Lots of the industrial establishments are owned by the government, instead of privacy. Consequently, the employees of these big corporation are considered as government workers. 
should be low. It is understandable, for the professionals are all employed by the government as high-level technicians. In light of the lower crude birth rate, beside the unique situation faced by Mainlander soldiers mentioned above, it is also expected to observe the negative association between professionals and fertility. To professionals, the cost of raising child is very high, and they could not invest as much as necessary to have a lot of children. Other characteristics of professionals, such as higher education and emphasis on the life quality of the middle class, also account for the low fertility. This is the very emergence of so-called single-urban-noble class and young couples with no children living in the city.

The second factor, commercial activity, associates: percentage of employers, (2) percentage of administrative and managerial workers, (3) percentage of clerical and related workers, (4) total land value, (5) percentage of sales workers, 6) population density, (7) percentage of divorced population aged 15-64, with a high negative loading for (8) percentage of production and related workers (see Table II).

Typically, the commercial activity associates with the area of highest land values in city. Only those activities whose profits are high can locate in this area of high land value. 
TABLE II

ROTATED FACTOR PATTERN OF UNDERLYING SPATIAL FACTORS IN KAOHSIUNG CITY, 1982

\begin{tabular}{|c|c|c|c|}
\hline VARIABLE NAME & PROFESSIONALS & $\begin{array}{r}\text { COMMERCIAL } \\
\text { ACT IVITY }\end{array}$ & COMMUNALITY \\
\hline $\begin{array}{l}\text { \% Government } \\
\text { Employees }\end{array}$ & 0.81949 & & 0.839979 \\
\hline $\begin{array}{l}\text { \% of High School } \\
\text { Graduates }\end{array}$ & 0.75152 & & 0.734957 \\
\hline $\begin{array}{l}\% \text { of Non-native } \\
\text { Res idents }\end{array}$ & 0.71772 & & 0.619850 \\
\hline $\begin{array}{l}\text { \% of University or } \\
\text { Col lege Graduates }\end{array}$ & 0.69538 & & 0.739812 \\
\hline $\begin{array}{l}\text { \% of Professional \& } \\
\text { Technical Workers }\end{array}$ & 0.64622 & & 0.696884 \\
\hline $\begin{array}{l}\% \text { of Service } \\
\text { Workers }\end{array}$ & -0.21180 & & 0.108635 \\
\hline \% of Self Employed & -0.46565 & & 0.486277 \\
\hline Crude Birth Rate & -0.50834 & & 0.432161 \\
\hline $\begin{array}{l}\% \text { of Private } \\
\text { Employees }\end{array}$ & -0.51045 & & 0.633261 \\
\hline $\begin{array}{l}\% \text { of Agricultural \& } \\
\text { Related Workers }\end{array}$ & -0.59957 & & 0.526125 \\
\hline $\begin{array}{l}\% \text { of Primary School } \\
\text { Graduates }\end{array}$ & -0.72166 & & 0.687746 \\
\hline$\%$ of Employers & & 0.74634 & 0.591864 \\
\hline $\begin{array}{l}\text { \% of Administrative, } \\
\text { Manager ial Workers }\end{array}$ & & 0.70303 & 0.559097 \\
\hline $\begin{array}{l}\% \text { of clerical \& } \\
\text { Related Workers }\end{array}$ & & 0.69433 & 0.527212 \\
\hline Total Land Value & & 0.68797 & 0.714514 \\
\hline$\%$ of Sales Workers & & 0.55455 & 0.594695 \\
\hline Population Density & & 0.47033 & 0.310834 \\
\hline $\begin{array}{l}\% \text { of Divorced Pop } \\
\text { Aged } 15-64\end{array}$ & & 0.36520 & 0.306573 \\
\hline $\begin{array}{l}\% \text { of Production \& } \\
\text { Related Workers }\end{array}$ & & -0.78830 & 0.719178 \\
\hline Eigenvalue & 5.610834 & 4.874481 & \\
\hline
\end{tabular}


TABLE II

ROTATED FACTOR PATTERN OF UNDERLYING SPATIAL FACTORS IN KAOHSIUNG CITY, 1982

(continued)

\begin{tabular}{|c|c|c|c|}
\hline VARIABLE NAME & $\begin{array}{l}\text { DISADVANTAGEOUS } \\
\text { OPPORTUNITY }\end{array}$ & VICE & COMMUNALITY \\
\hline$\%$ of single Pop & 0.86305 & & 0.800637 \\
\hline $\begin{array}{l}\text { Aged } 15 \& \text { over } \\
\% \text { of Female Single }\end{array}$ & 0.71321 & & 0.566401 \\
\hline $\begin{array}{l}\text { Pop Aged over } 15 \\
\% \text { of Widows } \\
\text { Aged over } 15\end{array}$ & 0.67660 & & 0.613914 \\
\hline $\begin{array}{l}\% \text { of Population } \\
\text { Aged over } 15\end{array}$ & 0.65506 & & 0.557512 \\
\hline $\begin{array}{l}\% \text { of Poverty } \\
\text { Households }\end{array}$ & 0.48837 & & 0.492831 \\
\hline $\begin{array}{l}\text { \% of single } \\
\text { Households }\end{array}$ & 0.46874 & & 0.570493 \\
\hline $\begin{array}{l}\text { \% Population } \\
\text { Aged } 15-64\end{array}$ & 0.43671 & & 0.416289 \\
\hline Crude Death Rate & 0.33621 & & 0.145110 \\
\hline $\begin{array}{l}\% \text { of Pop not in } \\
\text { School Aged } 6-15\end{array}$ & 0.24112 & & 0.150757 \\
\hline $\begin{array}{l}\% \text { of Populat ion } \\
\text { Aged } 0-4\end{array}$ & -0.23765 & & 0.111482 \\
\hline $\begin{array}{l}\text { \% of Fanily } \\
\text { Households }\end{array}$ & -0.43453 & & 0.537489 \\
\hline $\begin{array}{l}\text { Net Migration Rate } \\
\text { Inter Precincts }\end{array}$ & -0.57106 & & 0.418064 \\
\hline $\begin{array}{l}\text { Net Migration } \\
\text { Rate }\end{array}$ & -0.58050 & & 0.425321 \\
\hline Crime Rate & & 0.90635 & 0.895700 \\
\hline Sedition Rate & & 0.77636 & 0.643409 \\
\hline $\begin{array}{l}\text { Property Cr ime } \\
\text { Rate }\end{array}$ & & 0.69817 & 0.718829 \\
\hline $\begin{array}{l}\text { Prostitution } \\
\text { Crime Rate }\end{array}$ & & 0.66875 & 0.451398 \\
\hline $\begin{array}{l}\text { Other Crime } \\
\text { Rate }\end{array}$ & & 0.66016 & 0.513182 \\
\hline $\begin{array}{l}\text { Violent Crime } \\
\text { Rate }\end{array}$ & & 0.59426 & 0.536319 \\
\hline
\end{tabular}

Eigenvalue

4.699658

3.995217

Note: $F$ inal Communal ity Estimates: Total $=27.703187$ Rotation Method: Varimax 
TABLE II

ROTATED FACTOR PATTERN OF UNDERLYING SPATIAL
FACTORS IN KAOHSIUNG CITY, 1982
(continued)

\begin{tabular}{|c|c|c|c|c|}
\hline VARIABLE NAME & $\begin{array}{l}\text { FEMALE LABOR } \\
\text { PARTICIPATION }\end{array}$ & DISABILITY & $\begin{array}{l}\text { EMPLOYMENT } \\
\text { OPPORTUNITY }\end{array}$ & COMMUNAL I TY \\
\hline $\begin{array}{l}\% \text { of Female Pop } \\
\text { Economic Active }\end{array}$ & 0.83616 & & & 0.753500 \\
\hline $\begin{array}{l}\text { Economically } \\
\text { Inactive Rate }\end{array}$ & -0.83674 & & & 0.810094 \\
\hline $\begin{array}{l}\% \text { of old and } \\
\text { sick }\end{array}$ & & 0.85562 & & 0.812801 \\
\hline$\%$ of Housekeepers & & 0.83487 & & 0.706599 \\
\hline $\begin{array}{l}\text { \% of Unpaid Family } \\
\text { Members }\end{array}$ & & 0.45017 & & 0.309721 \\
\hline $\begin{array}{l}\% \text { of Male Economic } \\
\text { Act ive Pop. }\end{array}$ & & -0.55436 & & 0.828294 \\
\hline $\begin{array}{l}\text { \% of Female } \\
\text { Housekeepers }\end{array}$ & & -0.62279 & & 0.677483 \\
\hline $\begin{array}{l}\text { Employment Rate } \\
\text { of Male }\end{array}$ & & & 0.87227 & 0.833935 \\
\hline Employment Rate & & & 0.81386 & 0.685762 \\
\hline $\begin{array}{l}\text { Amount of Public } \\
\text { Infrastructure }\end{array}$ & & & 0.23324 & 0.201755 \\
\hline $\begin{array}{l}\text { Unemployment Rate } \\
\text { of Economic Active }\end{array}$ & & & -0.72507 & 0.688451 \\
\hline
\end{tabular}

$\begin{array}{llll}\text { Eigenvalue } & 3.046830 & 2.780751 & 2.695416\end{array}$

Note: $F$ inal Communality Est imates: Total $=27.703187$ Rotation Method: Varimax 
Simultaneously, the characteristics of population are primarily participating businessmen and related workers, such as employers, sales people and, administrative, managerial, and clerical workers. By contrast, production workers or coolies can hardly be found in the business area because they cannot find appropriate jobs. Another feature of the areas dominated by commercial activity is high population density. People gather together for jobs and business, and only the meeting with minimum economic scale of population size can support the commercial activity.

It is interesting, but unfortunate, to observe the association between the divorce rate and commercial activity in Kaohsiung city. There are several explanations that are responsible for this phenomenon. In general, those who engage in business are often exposed to high pressure environments, due to inhumane competition for profits. Such pressure tends to result in high risk of broken family. Moreover, recently, Taiwanese have been seriously criticized as "the richest without soul" after the success of economic miracle. It is true that Taiwan has made economic progress at the expense of accomplishing cultural and social modernization. Right now, Taiwanese always emphasize the quantity and material aspects, rather than the quality and spiritual dimensions. Such overemphasis on material satisfaction not only causes the increasing rate of divorce, but also creates a series of social problems, such as broken 
family, environmental decay, and psychological imbalance. It is believed that these social problems will require the Taiwanese to pay enormous cost to recover, and this cost can not be balanced by their economic success.

The third factor is called disadvantageous opportunity structure, which consists of: (1) percentage of single population aged 15 and over; (2) percentage of female single population aged over 15; (3) percentage of widows aged over 15; (4) percentage of population aged over 15; (5) percentage of households in poverty; (6) percentage of single household; (7) percentage of population aged 15 to 64; (8) crude death rate; (9) percentage of population not in school aged 6 to 15; (10) percentage of population aged 0 to 4; (11) percentage of family households; (12) net migration rate inter-precinct; and (13) net migration rate. The last four variables have negative correlation with this factor (see Table II).

obviously, the third group of variables indicates those who are not successful in the city. These people usually are single or unmarried, or have suffered the death of their spouse. The chance of having children thus becomes low and most of them are single households. Because of their ill success in the city, they are poor and have no money to let their children go to school, or they need their children to work to support the household, so that the percentage of population aged 6 to 15 not in school is high. In addition, 
their poverty results in not only less opportunity to move or migrate, but also a higher death rate due to the lack of good food and medical care. This characteristic may be consistent with Gans's type four group, i.e., the trapped and the downwardly mobile. Several phenomenon can explain the case of disadvantageous opportunity structure in Kaohsiung city.

Two mechanisms of Kaohsiung city take the central and dominant place in Taiwan: industrial (manufacturing) and military. It is understandable that the participants and incumbents of either manufacturing or military service are overwhelmingly the active labor force. Hence, in Table II, the proportion of people aged 15 to 64 is positively associated with the factor of disadvantageous opportunity structure. However, this group of population has encountered certain disadvantageous opportunity structure, particularly that associating with the family and marriage life.

First, it is necessary to examine the situation of workers. The productive activities within the working place of manufacturing have long been observed as inhumane, routinized, alienated, and impersonalized. Among these descriptions, one thing is especially important, that is, the workers usually spend day and night at the working place. In order to take the maximized profit of productivity, the three-eight system is popularly adopted in 
the manufacturing industry in Taiwan. Moreover, during the take-off stage of economic development, "holiday" and "weekend" was a wasted notion to both Taiwanese boss and workers. It is not too difficult to imagine the daily life situation of workers under such circumstance. One serious consequence of the day-and-night working is the impossibility of marriage. On the one hand, the workers usually have no time for dating, not mention to the finding of date-mate. Several years ago, some of the reports regarding the demand and supply of labor force in Taiwan had warned that the shift on switch rate of female workers are so high due to attempt to find date-mates. In order to make success in career, they, on the other hand, often delay marriage or even remain single. Of course, the high proportion of single will indispensably result in low proportion of young children in the population.

Many of the manufacturing industries in Kaohsiung are heavy industry, and the workers in these industries are exposed to a high risk of accidents. Miserable stories about the death of the head of household are routinely reported in the newspaper. On average, the death rate is extraordinarily high among the manufacturing workers. Consequently, the risk of widowhood is also significantly associated (see Table II).

There is another group of people that is strongly associated with the disadvantageous opportunity structure in 
Kaohsiung city. As mentioned above, military service workers and soldiers occupy an important proportion of population in this city. These armed labor force are seriously faced with the disadvantageous market structure of marriage, especially for those low-rank soldiers. They are mainly mainlander-immigrants and poor. It is hardly possible to have the opportunity to get a bride of native Taiwanese. Furthermore, some of them already had wives remaining in China mainland before they immigrated to Taiwan in 1949. Thus, the veteran villages are usually dominated by single men. Recently, the single, poor, and sick veteran has become a critical social welfare problem in Taiwan. Logically, the area characterized by disadvantageous opportunity structure will not attract migration either of short-distance or long-distance. Moreover, most of such areas in Kaohsiung city are either military-reserved or industrial land. The migration is substantially limited and prevented.

High crime rate is typically a negative description of urban life. This social problem is seen as the symptom of social disorganization or breakdown of the urban area. This forth underlying factor is also discovered in the analysis. Various crimes or delinquencies show high positive association in Table II, which is composed of factor four, delinquency. These variables include: (1) crime rate; sedition rate; (3) property crime rate; (4) prostitution 
crime rate; (5) other crime rate; and (6) violent crime rate.

Before 1980, the sedition crime was considered as the felony under the enforcement of military law. This crime covers a wide range of delinquencies, including interference with the performance of official duties, interference with personal freedom, disturbing the peace, insurgency, treason, trafficking in drugs, racket, contravention, and so on. All kinds of these delinquencies are controlled by two important law and measures: Anti-graft Regulations and Regulations Governing the Punishment of Seditious Elements. The property crime includes those governed by civil laws, and this kind of crime has increasingly become the most serious social problem, accompanied by the economic progress. Prostitution crime includes both the detrimental to public morale and offence against the family. Kaohsiung city is one of the few cities in Taiwan that faces the threat of a prostitution problem, because of the disproportionate sex ratio, and its seaport function.

It is worthy to notice the appearance of the unique dimension of delinquency and vice in underlying the differentiation of Kaohsiung city. The factor of crime does not interact with other factors, such as disadvantageous or poverty. It indicates that in Taiwan the crime is an exceptionally deviant case, and it has little association with other factors. However, it is also possible that the 
crimes is widely spread.

The fifth factor, female labor participation, consists of the percentage of female economically active population and the percentage of economically inactive people (see Table II). The former has positive correlation and the latter has negative correlation. One of the features of the metropolitan area is that there are various and adequate occupational opportunities, especially for female workers. Only a big city can supply more and different jobs for females. It is easy to understand that the economically active female population will be attracted to cities for their jobs. Cities are full of economic activities, the percentage of economically inactive people thus had a negative correlation.

Factor six, labeled as disability, is composed of five variables: (1) percentage of old and sick population; percentage of housekeepers; (3) percentage of unpaid family members; with negative loading for: (4) percentage of male economically active population; (5) percentage of female housekeepers.

on the whole, the living standard in the urban is said to be higher than that of non-urban area. However, the proportion of the poor and disadvantaged in the city is also over-represented. In fact, the city contains the richest as well as the poorest, and the city is also depicted as "concrete slum." This is also true in the Kaohsiung case. 
As we observed in Factor Six, disability, there are some disabled and disadvantaged populations living in Kaohsiung. These people are typically the appendix of the urban population--old, sick, housekeeper, ${ }^{19}$ and unpaid family workers.

The last factor, the employment opportunities, is represented by three positive variables and one negative variable. The three positive variables are: (1) employment rate of male; (2) employment rate; (3) amount of public infrastructure. The one negative variable is the unemployment rate of the economically active population. Cities always have better infrastructure, such as roads, railways, communication systems, etc. These become an important contribution to various businesses that create a lot of job opportunities, and thus employ many people. Thus the employment rate in the city is higher, and the unemployment rate lower.

Due to the adoption of orthogonal rotation method in factor analysis, the Pearson correlation coefficients among these seven factors are, of course, all almost zero. That is to say, these socio-economic underlying factors are intrinsically dependent and associated, and, hence, the orthogonal rotation method is used to present the most

${ }^{19}$ In Taiwan, the housewife, according to official definition, is classified as housekeeper in her occupation. There is extremely few proportion of this category who really participate in the housekeeping job. 
unique dimensions of them.

In sum, seven socio-economic underlying factors can be identified in this analysis to differentiate the residential structure in Kaohsiung city. And now, the question of concern is whether these socio-economic underlying factors are distributed ecologically, or, present certain spatial patterning. In the next section, the spatial patterning models discussed in the second chapter will be applied to explore the geographic distribution of these seven factors in subareas of Kaohsiung city.

SPATIAL PATTERNING OF RESIDENTIAL DIFFERENTIATION: RESULTS OF ANALYSIS OF VARIANCE

The purpose of this section is to examine the spatial distribution of seven socio-economic underlying factors extracted in last section to present the ecological pattern differentiating Kaohsiung city. Therefore, the first task in the following discussion is devoted to describe the spatial models and the modelling or mapping scheme in Kaohsiung city.

According to the discussion in the second chapter, three spatial patterning models are assumed in urban ecology: the concentric zone theory, sector theory, and multiple-nuclei theory. Basically, the concentric zone pattern and sector pattern can be clearly identified in terms of geographical or geometrical distance. As discussed in the Chapter III, the geographical distance sometimes 
cannot capture the real ecological distance between human beings. On the contrary, the multi-nuclei model seems to be more appropriate to present the ecological relationship and distance among human activities. However, in field study, the multi-nuclei model is difficult to define. Moreover, so far there is no information about the land use pattern in Kaohsiung city. Hence, only the zone and sector models are included in this study to examine the spatial patterning model in Kaohsiung city. This is still legitimate, for most of previously similar studies were devoted examining these two models (for example, Anderson and Egleland, 1961; and Timms, 1971).

After deliberate examination of the land use and social characteristics of Chicago in the early 1920s, Burgess suggested a five-circle model to summarize the urban pattern. These land use zones not only described the pattern at a particular point in time, but also represented the successive zones of urban expansion. Obviously, the mapping of concentric zones is based on the inductive examination of the land use pattern of the given city. Unfortunately, there is no such study of Kaohsiung city in extant literature, and the detailed information about the land use pattern is not available. Thus, after considering the current administrative boundaries of Kaohsiung municipality, five concentric circles were arbitrarily classified in terms of the geographical distance in 
Kaohsiung municipality. As discussed in the chapter IV, the current administrative boundary system in Taiwan reflects the human activities across the ecological territory. Figure 4 presents five concentric circles used to represent the concentric zones in Kaohsiung municipality. On Figure 4, the center of Kaohsiung is the location of Kaohsiung Municipality Hall, and each circle extends 1.5 kilometers outward.

In light of the sector model, transportation routs and the geography of the current city are most essential. According to this model, the land use patterns are observed to be distributed along the major transportation routes and to be modified or limited by the geography. On Figure 5, six sectoral zones are also arbitrarily identified in Kaohsiung municipality along the major transportation routes. In addition to the consideration of topography of the area, population distribution and historical socioeconomic condition, the sizes of these sectors are thus unequal. The first sector is the seaport area; the second is the manufacturing and related subarea; the third is the old subarea; the fourth is the new industrial park; the fifth is navy harbor area; and the last is the mountain area. However, it is necessary to mention that the land use pattern in Taiwanese cities is characterized by multiple and 


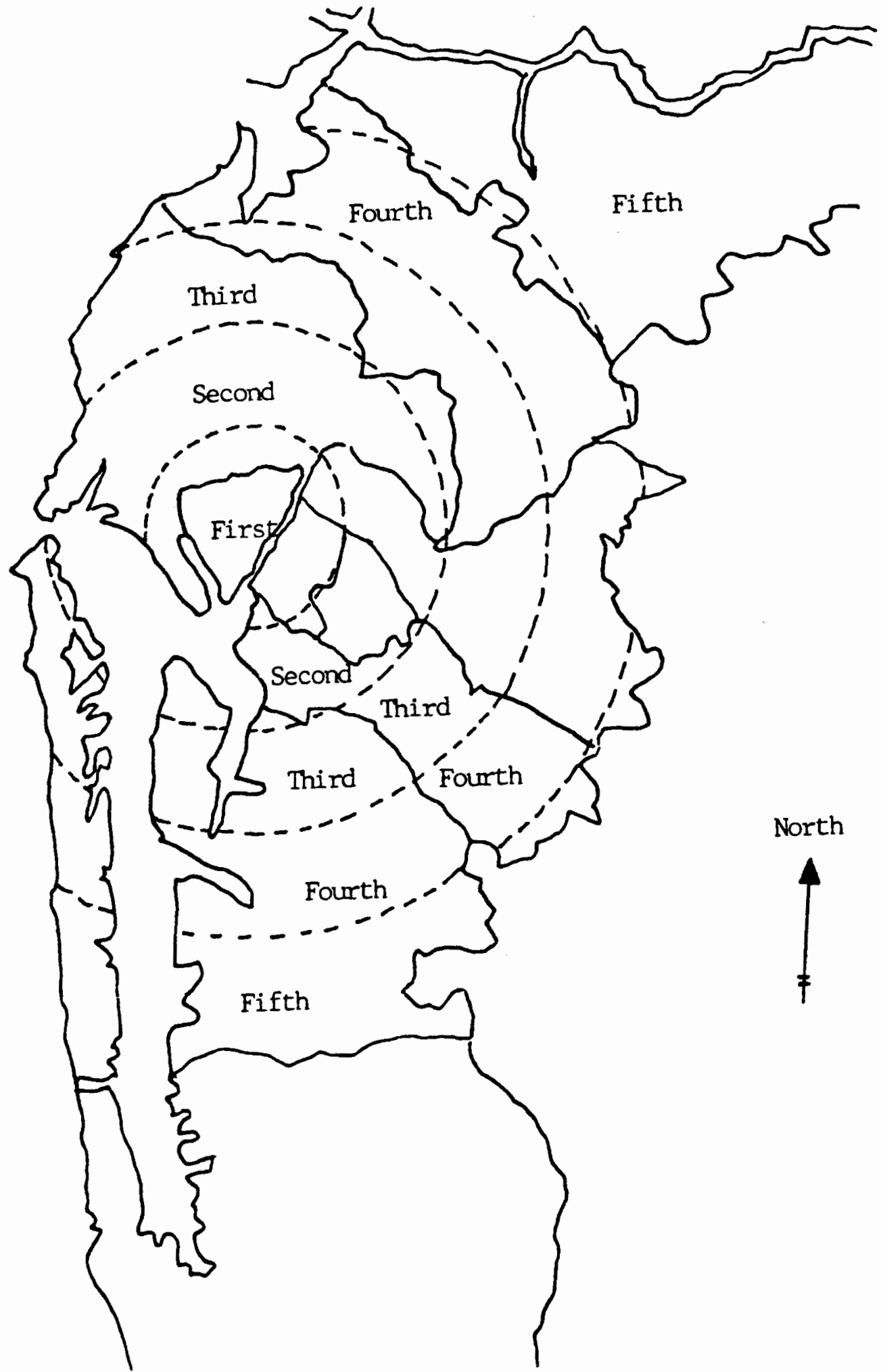

Figure 4. Concentric Circles in Kaohsiung Municipality. 


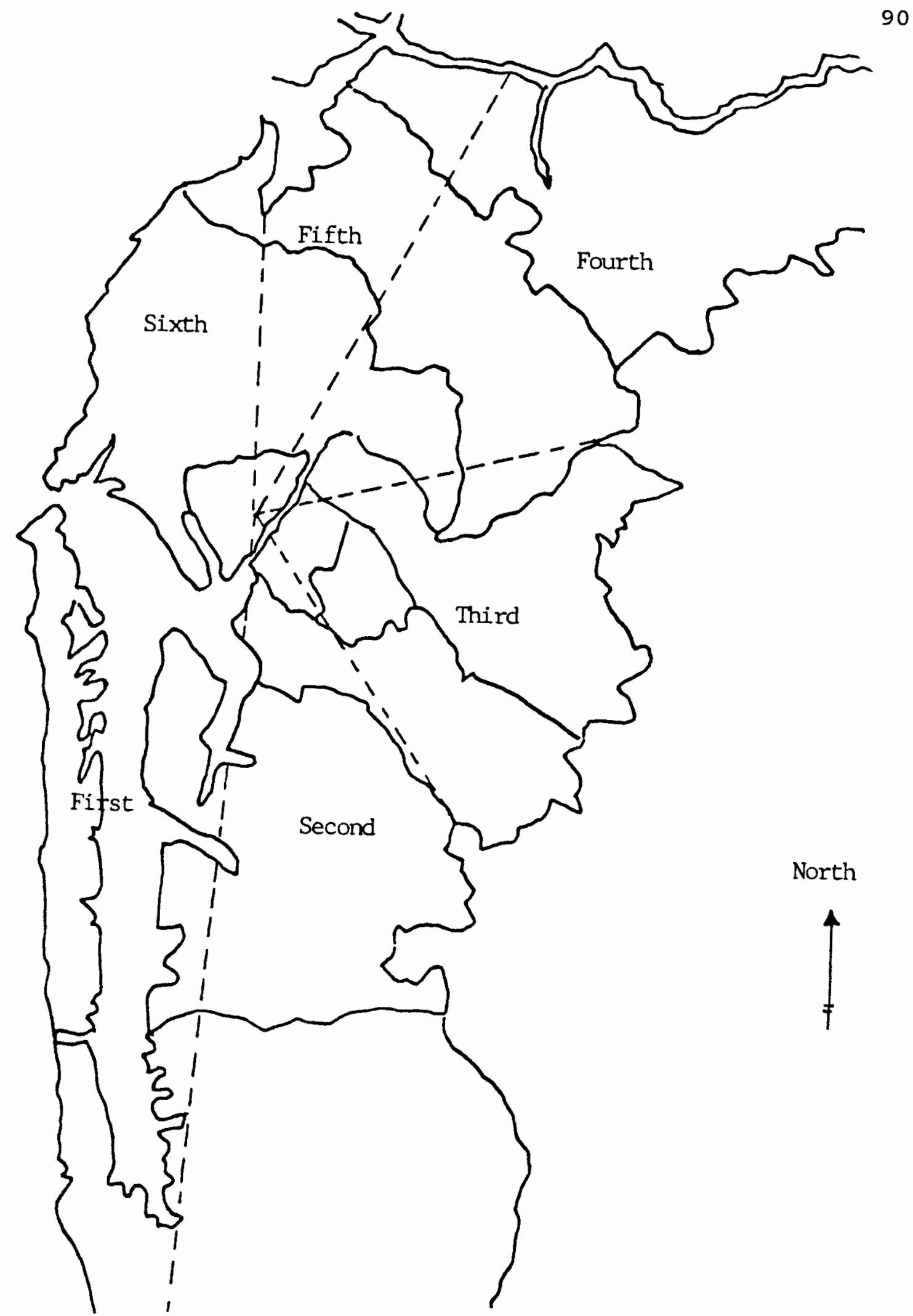

Figure 5. Sectoral Zones in Kaohsiung Municipality. 


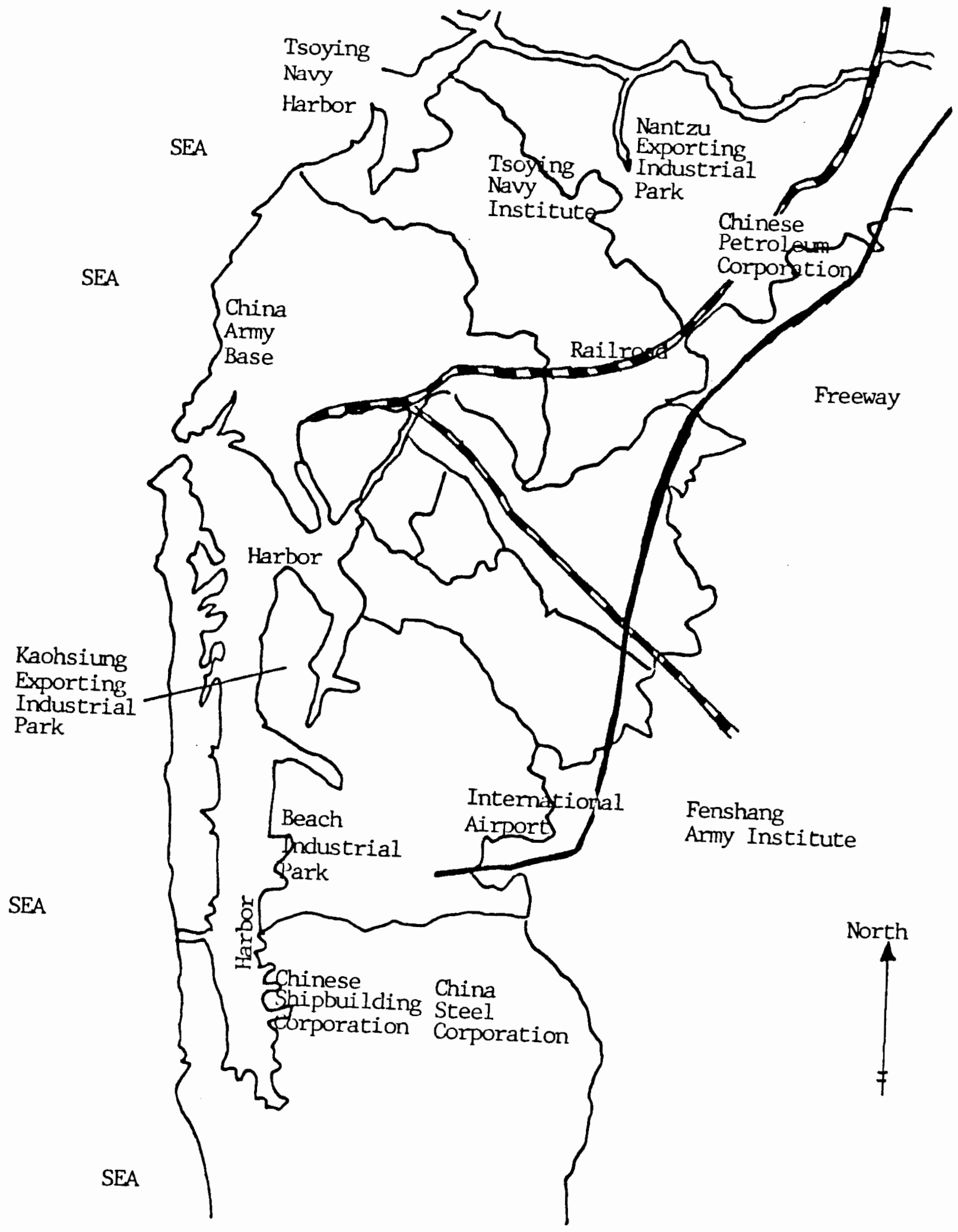

Figure 6. Major Establishments in Kaohsiung Municipality. 
mixed model, and there is no clear patterning that can be summarized.

Applying the factor analysis, investigators are usually not satisfied merely with the emerge of the underlying factors. The factor score is then constructed to represent the value of the underlying dimension for each LI. In practice, the factor is assumed to be a linear function of the constituant variables, and the expected factor score for each subject could be constructed by multiplying the factor loadings by corresponding standardized variable values for each LI. In this study, seven factors are discovered in the factor analysis, thus, the distribution of seven factor scores will be examined and analyzed in the remainder of this section.

Table III presents the mean scores of the seven factors by concentric zones and sectors defined. The distribution of these mean scores could be seen as the spatial patterning of the distribution of the socioeconomic underlying factors in Kaohsiung. The following will be the examination of these factor scores sequentially.

The first part is the examination of the concentric zone dimension. For the first factor, the fourth circle has the largest negative mean score. The fourth circle is the conventional fringe area of Kaohsiung city, and lots of farming-related residents occupy in this subarea. It is not unexpected to observe the largest negative score of the 
Table III

MEAN SCORES OF UNDERLYING SOCIOECONOMIC FACTORS BY CONCENTRIC ZONE AND SECTOR IN KAOHSIYNG CITY

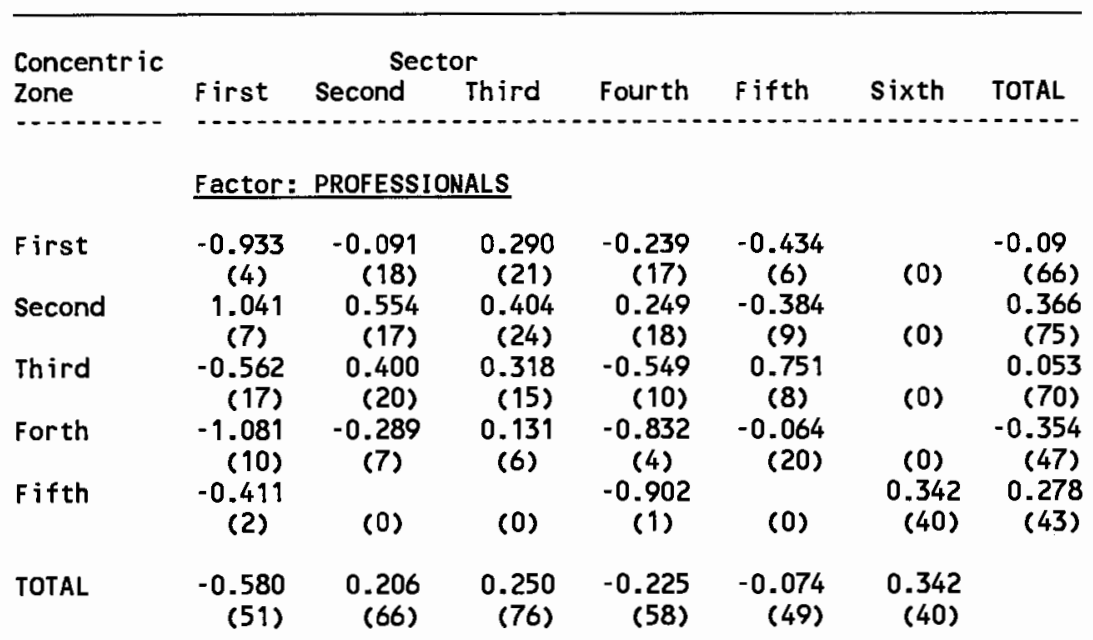

Factor: COMMERCIAL ACTIVITY

$\begin{array}{lccccccr}\text { First } & -1.078 & 0.161 & 1.014 & 0.670 & -0.368 & & 0.44 \\ & (4) & (18) & (21) & (17) & (6) & (0) & (66) \\ \text { Second } & -1.680 & 0.024 & 1.187 & 0.723 & -0.545 & & 0.337 \\ & (7) & (17) & (24) & (18) & (9) & (0) & (75) \\ \text { Third } & -1.165 & -0.442 & 0.151 & -0.046 & -0.727 & & -0.466 \\ & (17) & (20) & (15) & (10) & (8) & (0) & (70) \\ \text { Forth } & -0.889 & -0.726 & 0.137 & -0.210 & -0.334 & & -0.44 \\ & (10) & (7) & (6) & (4) & (20) & (0) & (47) \\ \text { Fifth } & -1.405 & & & -0.041 & & -0.666 & -0.686 \\ & (2) & & & (1) & & (40) & (43) \\ \text { TOTAL } & -0.904 & -0.133 & 0.914 & 0.540 & -0.393 & -0.666 & \end{array}$

Factor: DISADVANTAGEOUS OPPORTUNITY

\begin{tabular}{lccccccr} 
First & 1.319 & 0.396 & 0.371 & 0.137 & 1.059 & & 0.438 \\
& $(4)$ & $(18)$ & $(21)$ & $(17)$ & $(6)$ & $(0)$ & $(66)$ \\
Second & 1.009 & -0.396 & -0.111 & -0.786 & 0.044 & & -0.214 \\
& $(7)$ & $(17)$ & $(24)$ & $(18)$ & $(9)$ & $(0)$ & $(75)$ \\
Third & -0.239 & -0.860 & -0.423 & -0.902 & 0.175 & & -0.504 \\
& $(17)$ & $(20)$ & $(15)$ & $(10)$ & $(8)$ & $(0)$ & $(70)$ \\
Forth & -0.579 & -0.813 & -1.651 & -0.491 & 0.668 & & -0.213 \\
& $(10)$ & $(7)$ & $(6)$ & $(4)$ & $(20)$ & $(0)$ & $(47)$ \\
Fifth & -0.384 & & & -1.807 & & -0.147 & -0.197 \\
& $(2)$ & & & $(1)$ & & $(40)$ & $(43)$ \\
TOTAL & 0.223 & -0.236 & -0.036 & -0.293 & 0.608 & -0.147 & \\
& $(51)$ & $(66)$ & $(76)$ & $(58)$ & $(49)$ & $(40)$ & \\
\hline
\end{tabular}

Note: Values in parentheses are number of cases. 
Table III

MEAN SCORES OF UNDERLYING SOCIOECONOMIC FACTORS BY CONCENTRIC ZONE AND SECTOR IN KAOHSIYNG CITY (continued)

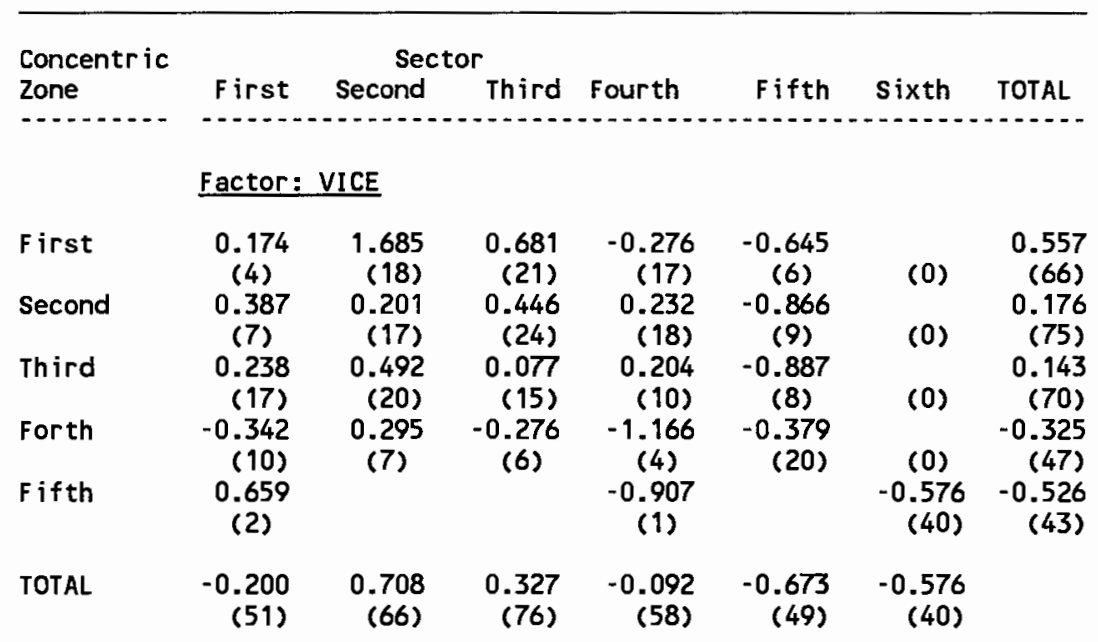

Factor: FEMALE LABOR FORCE PARTICIPATION

$\begin{array}{lccccccr}\text { First } & 0.194 & -0.393 & 0.030 & -0.073 & -0.125 & & -0.116 \\ & (4) & (18) & (21) & (17) & (6) & (0) & (66) \\ \text { Second } & 0.460 & 0.232 & -0.043 & 0.110 & 1.156 & & 0.247 \\ & (7) & (17) & (24) & (18) & (9) & (0) & (75) \\ \text { Third } & 0.682 & 0.582 & 0.469 & 0.681 & 0.429 & & 0.579 \\ & (17) & (20) & (15) & (10) & (8) & (0) & (70) \\ \text { Forth } & 0.086 & 0.289 & -0.049 & 0.563 & -1.038 & (4) & -0.339 \\ & (10) & (7) & (6) & (4) & (20) & (0) & (47) \\ \text { Fifth } & 0.911 & & & -2.040 & & -0.955 & -0.894 \\ & (2) & & & (1) & & (40) & (43) \\ & & & & & & & \\ \text { TOTAL } & 0.421 & 0.166 & 0.103 & 0.128 & -0.194 & -0.955 & \\ & (51) & (66) & (76) & (58) & (49) & (40) & \end{array}$

Factor: DISABILITY

\begin{tabular}{|c|c|c|c|c|c|c|c|}
\hline First & $\begin{array}{c}-0.381 \\
(4)\end{array}$ & $\begin{array}{r}-0.307 \\
(18)\end{array}$ & $\begin{array}{r}-0.011 \\
(21)\end{array}$ & $\begin{array}{r}-0.116 \\
(17)\end{array}$ & $\begin{array}{c}-0.263 \\
(6)\end{array}$ & (0) & $\begin{array}{r}-0.164 \\
(66)\end{array}$ \\
\hline Second & $\begin{array}{c}0.063 \\
(7)\end{array}$ & $\begin{array}{r}0.010 \\
(17)\end{array}$ & $\begin{array}{r}-0.116 \\
(24)\end{array}$ & $\begin{array}{r}-0.063 \\
(18)\end{array}$ & $\begin{array}{c}-0.058 \\
\text { (9) }\end{array}$ & (0) & $\begin{array}{r}-0.051 \\
(75)\end{array}$ \\
\hline Third & $\begin{array}{r}-0.401 \\
(17)\end{array}$ & $\begin{array}{r}0.130 \\
(20)\end{array}$ & $\begin{array}{r}-0.100 \\
(15)\end{array}$ & $\begin{array}{r}0.079 \\
(10)\end{array}$ & $\begin{array}{c}-0.126 \\
(8)\end{array}$ & (0) & $\begin{array}{r}-0.085 \\
(70)\end{array}$ \\
\hline Forth & 0.031 & -0.233 & 0.298 & 0.021 & 0.097 & & 0.053 \\
\hline Fifth & $\begin{array}{c}-0.281 \\
(2)\end{array}$ & & & $\begin{array}{c}-0.357 \\
\text { (1) }\end{array}$ & & $\begin{array}{r}0.554 \\
(40)\end{array}$ & $\begin{array}{r}0.494 \\
(43)\end{array}$ \\
\hline Total & $\begin{array}{r}0.256 \\
(51)\end{array}$ & $\begin{array}{r}-0.069 \\
(66)\end{array}$ & $\begin{array}{r}-0.005 \\
(76)\end{array}$ & $\begin{array}{r}0.001 \\
(58)\end{array}$ & $\begin{array}{r}-0.085 \\
(49)\end{array}$ & $\begin{array}{r}0.554 \\
(40)\end{array}$ & \\
\hline
\end{tabular}

Note: Values in parentheses are number of cases. 
Table III

MEAN SCORES OF UNDERLYING SOCIOECONOMIC FACTORS BY CONCENTRIC ZONE AND SECTOR IN KAOHSIYNG CITY

(continued)

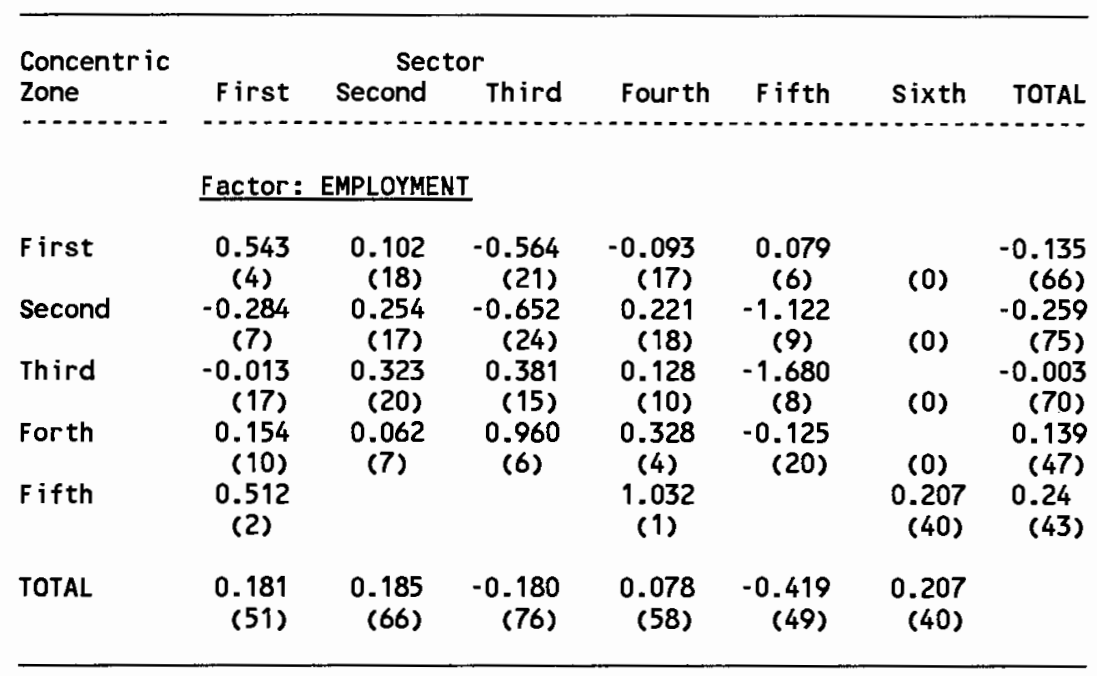

Note: Values in parentheses are number of cases.

professional in this area. The first circle could be referred as the central business area, consequently, it will not contain large proportion of the professionals. on the contrary, the second circle is now the high-class and most desirable residence area in Kaohsiung. With respect to the fifth circle, most of the major high-tech industrial establishments are located in this subarea, and it is foreseeable to have certain proportion of the professionals living in the nearby areas.

The score of commercial activity factor is clearly declining outwardly from the city center along the concentric circles (see Table III). The commercial function is obviously essential in the central area, and its 
importance is waning and declining along with distance from the city center. Simultaneously, the central circle also is the area containing the most disadvantaged opportunity structure (see Tables III). Vice and delinquency is strongly associated with the concentric circles, too. Specifically, the vice factor score declines with distance from the city center. The central circle has the highest vice score, and the fifth has the lowest. The other three factors seem to be also strongly associated with the concentric zone model. Typically, the inner circles have better employment opportunity and less disable structure. The association of the factor scores with the sector model is also evident. Professionals predominate in sectors 2, 3, and 6 . Commercial activity is over-represented in sections 3 and 4, while disadvantageous opportunity scores high in sectors 1 and 5 . Vice is heavily concentrated in sector 2 and female employment rates, disability and employment are more evenly distributed across all sectors than other factors.

In Table III, the first factor, professionals, spreads over zones 2 and 5. Kaohsiung's professionals live in Burgess' zone of transition and the zone of independent workingmen's houses. It is somewhat consistent with Burgess's theory. There are some roomy houses in the transition zone inhabited by government employees and professionals. And the professionals in this zone have easy 
access to work, and can escape from the transition zone. But in Taiwan, the employees of the government and of large enterprises may live in dormitories or in some particular area provided and designed by these organizations. Thus in sector analysis, these professionals live mainly in three sectors; i.e., sectors 2, 3, and 6. In Hoyt's view, these sectors might be along the main transportation routes, the professionals tend to reside along main roads.

Nevertheless, professionals tend to live in certain areas not very far from the $C B D$.

In classic ecology, the central business district is the center of commercial activity. The second factor, commercial activity, is very consistent with this view. The means of the second factor gradually decrease from zone one to zone five. In other words, commercial activities in Kaohsiung concentrate primarily on the central business district; the farther from the central circle area, the fewer the commercial activities. In the sector model, the commercial activities distribute mainly in sectors three and four. In sum, the commercial activities are prominent in certain sectors, but decrease more and more from the central circle subarea to the, edge of Kaohsiung city.

Disadvantageous opportunity, the third factor, is also significant in both models. In the concentric zone model, the factor basically distributes in the CBD and the areas encircling the $\mathrm{CBD}$. Burgess saw the poverty regions as 
primarily located in the transition zone, and Kaohsiung more or less exhibits this tendency. In the sector model, disadvantageous opportunity tends to occur in sectors 1 and 5 , but especially in sector 5; the disadvantaged and similarly situated socioeconomic population will live in certain areas. These sectors might have this character. In other words, those who are not successful in society usually gather together in some areas located in parts of the CBD and its adjoining district in Kaohsiung.

Factor 4, vice, is mainly found higher in inner circles and lower levels at the edge of the city. According to concentric zone theory, the transition zone consists of the principal slums with their submerged regions of poverty, degradation, and disease, and their underworld of vice. In addition, the zone of better residence and the commuters' zone have a higher socio-economic class residents, so there are few criminal activities. Zones 4 to 5 also have this tendency. However, in sector model, vice occurs mainly in sectors 2 and 3 . The criminal activities generally take place in certain areas. But the areas of delinquency are not necessarily connected with the low socio-economic population. It may be understood by comparing the sectors of this factor and the third factor.

In Table III, female labor participation tends to decrease from the CBD: outwardly to the edge of the city. Usually female labor is more acceptable and necessary in the 
central business district. There are more commercial activities in the center of the city, and thus more opportunity for women to have a jobs. Therefore, higher female labor participation results. Similar finding is also found in the factor of employment, but it is inharmonious with Burgess's view. In a comparison with Burgess's counterpart, the outer zones might be either the zone of better residences, or the zone of commuters, which is not the zone of high employment area. However, the sector theory might explain that these sectors are along the better access ways and have better infrastructure for certain businesses.

Examining Table III, it is evident that the main effects of either concentric zone or sector model are significant, but certain interaction effects can also be observed. However, the distribution of the mean scores cannot clearly show the significance of the real picture. Thus, a two-way ANOVA was conducted to examine the mean scores difference. However, because the sizes of sectors are unequal, there is a limitation derived from unequal cell means. The interpretations of the interaction between zones and sectors are restricted in some degree. Especially, the sixth sector only has tracts in fifth zone. The interpretation of the interaction between them, therefore, should be interpreted more carefully. Table IV presents the results of the analysis of variance. 
Table IV

TOW-WAY ANOVA ON UNDERLYING FACTORS BY CONCENTRIC ZONE AND SECTOR

$\begin{array}{lrrrrrr}\begin{array}{l}\text { Dependent Variable: PROFESSIONALS } \\ \text { Source }\end{array} & \text { DF } & \begin{array}{r}\text { Sum of } \\ \text { Squares }\end{array} & \begin{array}{r}\text { Mean } \\ \text { Square }\end{array} \\ \text { Model } & 23 & 85.17317052 & 3.70318133 & 4.61 & 0.0001 & 0.251248 \\ \text { Error } & 316 & 253.82682948 & 0.80324946 & & & \\ \text { Corrected Total } & 339 & 339.00000000 & & & & \\ \text { CONCENTRIC ZONE } & 4 & 12.33001772 & 3.08250443 & 3.84 & 0.0046 & \\ \text { SECTOR } & 5 & 34.23180749 & 6.84636150 & 8.52 & 0.0001 & \\ \text { ZONE*SECTOR } & 14 & 38.61134531 & 2.75795324 & 3.43 & 0.0001\end{array}$

Dependent Var iable: COMMERCIAL ACTIVITY

$\begin{array}{lrrrrrr}\text { Source } & \text { DF } & \begin{array}{r}\text { Sum of } \\ \text { Squares }\end{array} & \begin{array}{r}\text { Mean } \\ \text { Square F Value }\end{array} & \text { Pr }>\text { F } & \text { R-Square } \\ \text { Model } & 23 & 205.0544484 & 8.9154108 & 21.03 & 0.0001 & 0.604880 \\ \text { Error } & 316 & 133.9455516 & 0.4238783 & & & \\ \text { Corrected Total } & 339 & 339.0000000 & & & & \\ \text { CONCENTRIC ZONE } & 4 & .84 .5932494 & 21.1483123 & 49.89 & 0.0001 & \\ \text { SECTOR } & 5 & 100.2788167 & 20.0557633 & 47.31 & 0.0001 & \\ \text { ZONE*SECTOR } & 14 & 20.1823824 & 1.4415987 & 3.40 & 0.0001 & \end{array}$

Dependent Variable: DISADVANTAGEOUS OPPORTUNITY

$\begin{array}{lrrrrrr}\text { Source } & \text { DF } & \begin{array}{r}\text { Sum of } \\ \text { Squares }\end{array} & \begin{array}{c}\text { Mean } \\ \text { Square }\end{array} & \text { value } & \operatorname{Pr}>\text { F } & \text { R-Square } \\ \text { Model } & 23 & 144.0728851 & 6.2640385 & 10.15 & 0.0001 & 0.424994 \\ \text { Error } & 316 & 194.9271149 & 0.6168580 & & & \\ \text { Corrected Total } & 339 & 339.0000000 & & & & \\ & & & & & & \\ \text { CONCENTRIC ZONE } & 4 & 83.84791636 & 20.96197909 & 33.98 & 0.0001 & \\ \text { SECTOR } & 5 & 37.12399073 & 7.42479815 & 12.04 & 0.0001 & \\ \text { ZONE*SECTOR } & 14 & 23.10097802 & 1.65006986 & 2.67 & 0.0010 & \end{array}$

Dependent Var iable: VICE

$\begin{array}{lrrrrrr}\text { Source } & \text { DF } & \begin{array}{r}\text { Sum of } \\ \text { Squares }\end{array} & \begin{array}{r}\text { Mean } \\ \text { Square }\end{array} & F \text { value } & \operatorname{Pr}>F & R \text {-square } \\ \text { Model } & 23 & 138.5308952 & 6.0230824 & 9.49 & 0.0001 & 0.408646 \\ & 316 & 200.4691048 & 0.6343959 & & & \\ \text { Error } & 339 & 339.00000000 & & & & \\ \text { Corrected Total } & & & & & & \\ & 4 & 47.97957709 & 11.99489427 & 18.91 & 0.0001 & \\ \text { CONCENTRIC 2ONE } & 5 & 51.48100140 & 10.29620028 & 16.23 & 0.0009 & \\ \text { SECTOR } & 14 & 39.07031669 & 2.79073691 & 4.40 & 0.0001 & \\ \text { ZONE*SECTOR } & & & & & & \end{array}$


Table IV

TOW-WAY ANOVA ON UNDERLYING FACTORS BY CONCENTRIC ZONE AND SECTOR

(continued)

\begin{tabular}{|c|c|c|c|c|c|c|}
\hline \multirow[t]{2}{*}{ Dependent Variabl } & FEMALE & \multicolumn{2}{|c|}{ LABOR FORCE PARTICIPATION } & \multirow[b]{2}{*}{ F Value } & \multirow[b]{2}{*}{$\operatorname{Pr}>\mathrm{F}$} & \multirow[b]{2}{*}{ R-Square } \\
\hline & DF & $\begin{array}{l}\text { Sum of } \\
\text { Squares }\end{array}$ & $\begin{array}{c}\text { Mean } \\
\text { Square } F\end{array}$ & & & \\
\hline Model & 23 & 107.1357628 & 4.6580766 & 6.35 & 0.0001 & 0.316035 \\
\hline Error & 316 & 231.8642372 & 0.7337476 & & & \\
\hline Corrected Total & 339 & 339.0000000 & & & & \\
\hline $\begin{array}{l}\text { CONCENTRIC ZONE } \\
\text { SECTOR } \\
\text { ZONE*SECTOR }\end{array}$ & $\begin{array}{r}4 \\
5 \\
14\end{array}$ & $\begin{array}{r}71.47614701 \\
5.52897426 \\
30.13064154\end{array}$ & $\begin{array}{r}17.86903675 \\
1.10579485 \\
2.15218868\end{array}$ & $\begin{array}{r}24.35 \\
1.51 \\
2.93\end{array}$ & $\begin{array}{l}0.0001 \\
0.1872 \\
0.0003\end{array}$ & \\
\hline \multicolumn{7}{|c|}{ Dependent Variable: DISABILITY } \\
\hline Source & DF & $\begin{array}{l}\text { Sum of } \\
\text { Squares }\end{array}$ & $\begin{array}{c}\text { Mean } \\
\text { Square } F\end{array}$ & F Value & $\mathrm{Pr}>\mathrm{F}$ & R-Square \\
\hline Model & 23 & 22.99543189 & 0.99980139 & 1.00 & 0.4651 & 0.067833 \\
\hline Error & 316 & 316.00456811 & 1.00001446 & & & \\
\hline Corrected Total & 339 & 339.00000000 & & & & \\
\hline $\begin{array}{l}\text { CONCENTRIC ZONE } \\
\text { SECTOR } \\
\text { ZONE*SECTOR }\end{array}$ & $\begin{array}{r}4 \\
5 \\
14\end{array}$ & $\begin{array}{r}11.21437367 \\
7.01955323 \\
4.76150499\end{array}$ & $\begin{array}{l}2.80359342 \\
1.40391065 \\
0.34010750\end{array}$ & $\begin{array}{l}2.80 \\
1.40 \\
0.34\end{array}$ & $\begin{array}{l}0.0260 \\
0.2225 \\
0.9882\end{array}$ & \\
\hline \multicolumn{7}{|c|}{ Dependent Variable: EMPLOYMENT OPPORTUNITY } \\
\hline Source & DF & $\begin{array}{l}\text { Sum of } \\
\text { squares }\end{array}$ & $\begin{array}{c}\text { Mean } \\
\text { Square } F\end{array}$ & F Value & $\mathrm{Pr}>\mathrm{F}$ & R-Square \\
\hline Model & 23 & 64.36213921 & 2.79835388 & 3.22 & 0.0001 & 0.189859 \\
\hline Error & 316 & 274.63786079 & 0.86910715 & & & \\
\hline Corrected Total & 339 & 339.00000000 & & & & \\
\hline $\begin{array}{l}\text { CONCENTRIC ZONE } \\
\text { SECTOR } \\
\text { ZONE*SECTOR }\end{array}$ & $\begin{array}{r}4 \\
5 \\
14\end{array}$ & $\begin{array}{l}12.27817331 \\
16.75260874 \\
35.33135717\end{array}$ & $\begin{array}{l}3.06954333 \\
3.35052175 \\
2.52366837\end{array}$ & $\begin{array}{l}3.53 \\
3.86 \\
2.90\end{array}$ & $\begin{array}{l}0.0077 \\
0.0021 \\
0.0004\end{array}$ & \\
\hline
\end{tabular}


By and large, all the models of ANOVA for seven factors are significant. Main effects and interaction effects between concentric zones and sectors are all significant, except the sector effects of female labor force participation and disability factors. It indicates that both the concentric zone and the sector model are significant in accounting for the spatial variation of the distribution of the socio-economic underlying factors in Kaohsiung city. Contrasting to previous studies, (Anderson and Egleland, 1961; Rees, 1970), the concentric zone and sector models differ in terms of the underlying dimensions. In these studies, the socio-economic dimension tends to form sectors, and the urbanization dimension tends to be distributed according to zones rather than sectors. In this study, almost all the underlying factors are significant both in concentric zone and in sector models, furthermore, the presence of the significant interaction effects shows the combination of concentric zone and sector models in Kaohsiung city.

Comparing Tables III and IV, a similar pattern for the concentric zone and sector model is found. Except for the fifth and sixth underlying factors, female labor force participation and disability, the analysis shows that each set of socio-economic and demographic criteria vary substantially both zonally and sectorially. In other words, the mean values of factor scores among concentric zones or 
sectors differ significantly (the F-ratio of all the models arrive at .0 critical level). This means that various combination of concentric zones and sectors have significant impacts on the spatial patterning of these underlying factors, except for disability and for female labor participation.

However, the explanatory power for the concentric zones and sectors to account for the variance in the location of those underlying factors varies dramatically. The R-Square coefficient in Table IV, shows the percentage of variance explained in a particular factor by both models. In the consideration of both models, commercial activity, factor 2 , has explained $60 \%$ of variance, but other factors are explained disproportionally. Both disadvantageous opportunity and vice have more than $40 \%$ of their variance explained by sectoral and concentric location models. Thirty percent of female labor participation has been explained. The other factors have all under 25\%, especially disability which has $7 \%$ of its variance explained. This means that the underlying factor of commercial activity in Kaohsiung city could be best explained by the concentric zone model combined with sector model, and the disadvantaged opportunity and vice factors can also be moderately explained. Notwithstanding, other factors, particularly the disability factor, cannot be satisfactorily explained either by concentric zone or sector model in Kaohsiung city. 
This analysis, however, neglects the gradient idea in Burgess' model and treats zones like sectors as nominal areas--not as ordered in any way. 
CHAPTER VI

CONCLUSION

SUMMARY OF FINDINGS

The purpose of this study was to uncover the latent constructs underlying the ecological dimension of Kaohsiung city in Taiwan. Factorial ecology was employed to discover the underlying factors. An array of forty-nine demographic, socioeconomic, and crime variables were collected and input in the factor analysis, and, finally, seven underlying factors were extracted. The seven underlying factors differentiating the ecological structure of Kaohsiung city are professional, commercial activity, disadvantageous opportunity, vice, female labor participation, disability, and employment opportunity. The cumulative eigen values account for $56 \%$ of the variation in the 49 variables selected for analysis.

with respect to the spatial distribution of these seven socio-economic underlying factors, the technique of two-way analysis of variance was applied to examine the concentric zone and sector models. Among these seven underlying factors, five show significance in concentric zone and sector organization as well as significant zone-sector 
interaction effects, and the other two are significant in only the concentric model. The five which appear to be organized both sectorially and zonally are: professionals, commercial activity, disadvantageous opportunity, vice and employment opportunity. Female labor participation and disability are only organized concentrically, in terms of the analytical findings of two-way ANOVA.

\section{DISCUSSION AND IMPLICATION OF RESEARCH FINDINGS}

The discovery of the underlying factors in factorial ecology is strongly affected by the input of independent variables. Although as many variables as possible are included, such bias remains and cannot be solved in this study. Nevertheless, research findings of this study can be used as a comparative case of a non-Western modern city. overall, the latent constructs underlying the ecological dimension of Kaohsiung city are economy-related attributes. Professional, commercial activity, and employment opportunity factors are best explained by this notion. This finding is especially meaningful in the Taiwanese case.

During the last four decades, Taiwan has developed successfully in her economy. Sociological studies of Taiwanese society find that social development in Taiwan has been overwhelmingly dominated by her economic development policy. Economic sector has been considered as the most important single-piece of the social structure in Taiwan, 
and the people of this island are labelled as the economic animals. 20 Such observation is clearly reflected in the case of urban development, as shown in this study. The research findings of analysis of variance in examining the spatial patterning of the socio-economic underlying constructs show that both the concentric zone model and sector model can explain some of the spatial patterning in Kaohsiung city. Moreover, the interaction effects between concentric zone and sector are also significant. Such findings reflect a unique land use pattern in Taiwan--multiple and mixed zoning. Urban planning had rarely occurred in most cities on the island since the development of cities. Zoning has been seen as segregation which is against the tradition of equal opportunity in Taiwanese society. In addition, special housing pattern mixes the commercial and residential inhabitants in most buildings. Most population lived in the apartments in Kaohsiung, and apartments usually contain

${ }^{20}$ Political activities and social movements are seriously prohibited on this island due to traditional political structure of the leadership as well as the political conflict and tension between Taiwan and china governments. Consequently, Taiwanese are encouraged to and can only participate in the success of economic activities. All the social activities have been transformed and absorbed into economic system. In fact, most aspects of the progress in social spheres can be attributed to economic factors. For example, the famous case of fertility decline in Taiwan since 1950s was found to be most successfully explained by the demand-and-supply theory of economics.

Sociologists are, thus, wondering about the dominance of economics in determining social behavior in Taiwan. 
offices in the lower levels, and residences in the others. As a result, the residential community is always mixed zoned. Recently, the government attempted to enforce the urban renewal policy, but it was strongly rejected by the people. However, this does not mean that there does not exist stratification or hierarchical system in Taiwanese society. Rather, it suggests that the ecological notion of geographical or geometrical distance is not appropriate in Taiwan, and other conceptions, such as social and psychological distance, may occupy a more important place in social differentiation.

In comparison with western cities, strong family relationship in Taiwan decreases the individual mobility and restricts the urbanization process. Family relationships also limit female labor participation and disability factors. The traditional culture, which considers family support a man's responsibility, discourages woman from working. Due to the lack of sufficient social welfare program, family in Taiwan usually has a function to take care disable members in the family. In addition, single ethnicity produces no racial segregation. Unfortunately, in this study, information about social and psychological distance is not available, hence, their importance and influence in determining social differentiation are not able to be evaluated. Further analysis with these data will be necessary to understand the spatial patterning of 
residential differentiation in Kaohsiung city. 
REFERENCES

Abu-Lughod, J. 1969. "Testing the Theory of Social Area Analysis: the Case of Cairo, Egypt," American

Sociological Review, $36(2), 198-211$.

Alihan, Milla A. 1938. Social Ecology: A Critical Analysis, Columbia University Press, New York.

Amato, P. 1970. "Elitism and settlement Patterns in the Latin-American City," Journal of American Institute of Town Planner, 36(1), 96-105.

Anderson, T. and Egleland, J. 1961. "Spatial Aspects of Social Area Analysis," American Sociological Review, $26,392-98$.

Bell, Wendell 1955. "Economic, Family and Ethnic status: An Empirical Test," American Sociological Review, 20, 45-52.

Berry, Brian J. 1965. "Internal structure of the city," Law Contemporary Problems, 3, 113-120.

1971. "Comparative Factorial Ecology," Supplement to Economic Geography, 2 .

Berry, Brian J. and Rees, Phillip 1968. "The Factorial Ecology of Calcutta," Unpublished mimeographed paper. University of Chicago, Department of Geography. Chicago.

Berry, Brian J. and Kasarda, John D. 1977. Contemporary Urban Ecology, Macmillan, New York.

Blumenfeld, Hann 1949. "On the concentric-cycle Theory of Urban Growth," Land Economics, 25, 209-212.

Brand, R. R. 1972. "The Spatial Organization of Residential Areas in Accra, Ghana, with Particular Reference to Aspects of Modernization," Economic Geography, 48, $284-298$.

Burgess, Ernest w. 1925. "The Growth of the City: An Introduction to a Research Project," in Robert $\mathrm{E}$. Park, Ernest W. Burgess and R. D. McKenzie (eds.), The City, University of Chicago Press, Chicago. 
Caplow, Theodore 1952. "Urban Structure in France," American Sociological Review 17, 544-549.

Christaller, walter 1933. The Central Circle in Suddeutschland, Gustave Fischer Verlag, Jena.

Crissman, Lawrence W. 1981. "The Structure of Local and Regional system," in Emily Martin Aherm and Hill Gates (eds.), The Anthropology of Taiwanese Society, Stanford University Press, Stanford. 89-124.

Davis, Maurice R. 1937. "The Pattern of Urban Growth," Studies in the Science of Society, edited by George Peter Murdick. Yale University Press, New Haven.

Duncan, otis Dudley. 1955. "Review of Social Area Analysis," American Journal of Sociology, 61, 84-85.

Durkheim, Emile 1964. Suicide. Free Press, Glencoe.

Felson, Marcus 1987. "Routine Activities and Crime Prevention in the Developing Metropolis," Criminology, 25, 911-31.

Firey, Walter 1945. "Sentiment and Symbolism as Ecological Variables," American Sociological Review, 10, 140-48.

1947. Land Use in Central Boston, Harvard University Press, Cambridge.

Gans, Herbert 1962. "Urbanism and Suburbanism as ways of Life: A Reevaluation of Definitions," Human Behavior and Social Processes, edited by A. M. Rose, Houghton Mifflin, New York. 625-648.

New York.

1962. The Urban Villagers. The free Press,

Gittus, Elizabeth 1965. "An Experiment in the Definition of Urban Sub-Areas," Transaction of the Bartlett Society, $2, \quad 109-135$.

Gosnell, H. and Schmidt, M. 1936. "Factorial and Correlational Analysis of the 1934 Vote in Chicago," American Statistical Association, 31, 507-518.

Groves, W. Byron, Newman, Graeme, and Corrado, Charles 1987. "Islam, Modernization and Crime: a Test of the Religious Ecology Thesis," Journal of Criminal Justice, 15, 495-503.

Haggerty, Lee J. 1971. "Another Look at Burgess Hypothesis: 
Time as an Important Variable," American Journal of sociology, 76, 1084-1093.

Hamm, Bernd 1982. "Social Area Analysis and Factorial Ecology: A Review of Substantive Findings," in George A. Theodorson (ed.), Urban Patterns: Studies in Human Ecology, The Pennsylvanian State University Press. 316-337

Harman, H. H. 1976. Modern Factor Analysis. University of Chicago press, Chicago.

Harris, Chauncy and Ullman Edward 1945. "The Nature of Cities," Annuals of the American Academy of Political and Social Science 242, 7-17.

Hawley, Amos H. 1950. Human Ecology: A Theory of Community Structure. Ronald Press, New York.

1971. Urban Society: An Ecological Approach, first edition, The Ronald Press, New York.

Hawley, Amos H, Duncan and otis Dudley. 1957. "Social Area Analysis: A Critical Appraisal," Land Economics, 33, $337-345$.

Hoyt, Homer 1939. "The Pattern of Movement of Residential Rental Neighborhoods," written by Homer Hoyt in The structure and Growth of Residential Neighborhoods in American Cities, Federal Housing Administration, Washington, D. C..

Janson, Carl-Gunnar 1980. "Factorial Social Ecology: An Attempt at Summary and Evaluation," Annual Reviews of Sociology, 6, 433-56.

Johnston, R. J. 1976. "Residential Area Characteristics: Research Method for Identifying Urban Sub-areas--Social Area Analysis and Factorial Ecology," in D. T. Herbert and R. J. Johnston, Social Areas in Cities, Vol.1 London: Wiley, 193-235.

London, B. and Flanagan, W. G. 1976. "Comparative Urban Ecology: A Summary of the Field," in J. Walton and $\mathrm{L}$. H. Masottie, eds., The City in Comparative Perspective, New York.

Losch, August 1954. The Economics of Location, Translated by W. H. Woglom, Yale University Press, New Haven. 105-34.

McKenzie R. D. 1926. "The Scope of Human Ecology," The American Sociological Society, 20, 141-54. 
1927. "The Concept of Dominance and World Organization," American Journal of Sociology, 33, 2842 .

Meyer, D. R. 1986. "System of Cities Dynamics in Newly Industrializing Nations," Studies in Comparative International Development, 21, 3-22.

Murdie, R. A. 1969. "Factorial Ecology of Metropolitan Toronto, 1951-61." Research Paper 116, Department of Geography, University of Chicago.

Park, Robert E. 1936. "Human Ecology," American Journal of Sociology, $42,1-15$.

York.

1952. Human communities, The Free Press, New

Pedersen, Paul 0. 1967. Model for Befolkningsstruktur og Befolkningsudvikling i storbyomraderspecielt Med Henblik Pa Storko benhavn, Danish text with English summary, state Planning Institute, Coperhagen.

Price, D. O. 1942. "Factor Analysis in the Study of Metropolitan Centers," Social Forces, 20, 449-455.

Quinn, James A. 1940. "The Burgess Zonal Hypothesis and its Critics," American Sociological Review, 15, 210-18.

Rees, P. H. 1970. "Concepts of Social Place: Toward an Urban Social Geography," In Brian J. Berry and F, Horton, eds., Geographic Perspectives on Urban Systems, Prentice-Hall, Englewood cliffs.

1972. "Problems of Classifying Subareas within Cities," In Brian J. Berry, ed., City Classification Handbook, John Wiley, New York.

Robson, Brian 1969. Urban Analysis: The Social Ecology of Sunderland, Cambridge University Press, Cambridge.

Salins, P. D. 1971. "Household Location Patterns in American Metropolitan Areas," Economic Geography, 47, 234-48.

Schmid, C. F. 1960. "Urban Crime Areas: Part II," American Sociological Review, 25, 655-78.

Schnore, Leo F. and Jones, Joy K. 1969. "The Evolution of City-Suburban Types in the course of a Decade," Urban Affairs Quarterly, 4, 421-422. 
Sherman, Lawrence W., Gartin, Patrick R. and Buerger, Michael E. 1989. "Hot Spots of Predatory Crime: Routine Activities and the Criminology of Place," Criminology, $27,27-55$.

Shevky, Eshref and Williams, Marilyn. 1949. The Social Areas of Los Angeles: Analysis and Topology, University of California Press, Los Angeles and Berkeley.

Shevky, E. and Bell, W. 1955. Social Area Analysis, Stanford University Press, Stanford.

Skinner, G. William. 1964. "Marketing and Social structure in Rural China: Part I," Journal of Asian studies $24(1), 32-43$.

Smith, David M. 1973. The Geography of Social Well-Being in the United States: An Introduction to Territorial Social Indicators, McGraw-Hill, New York.

Sweetser, F. L. 1965. "Factorial Ecology: Helsinki, 1960." Demography, 2, 372-385.

Timms, Duncan. 1971. The Urban Mosaic: Towards a Theory of Residential Differentiation, Cambridge University Press.

Van Arsdol, Maurice, Camilleri, Santo and Schmidt, Calvin. 1958. "The Generality of Urban Social Area Indexes," American Sociological Review, 23, 277-284.

Wirth, Louis. 1938. "Urbanism as a Way of Life," American Journal of Sociology, $44,1-24$.

Zorbaugh, Harvey W. 1926. "The Natural Areas of the City," The American Sociological Society, 20, 188-197. 
APPENDIX

UNIVARIATE STATISTICS OF VARIABLES

\begin{tabular}{|c|c|c|}
\hline Var iable Name & Mean & $\begin{array}{l}\text { Standard } \\
\text { Deviation }\end{array}$ \\
\hline 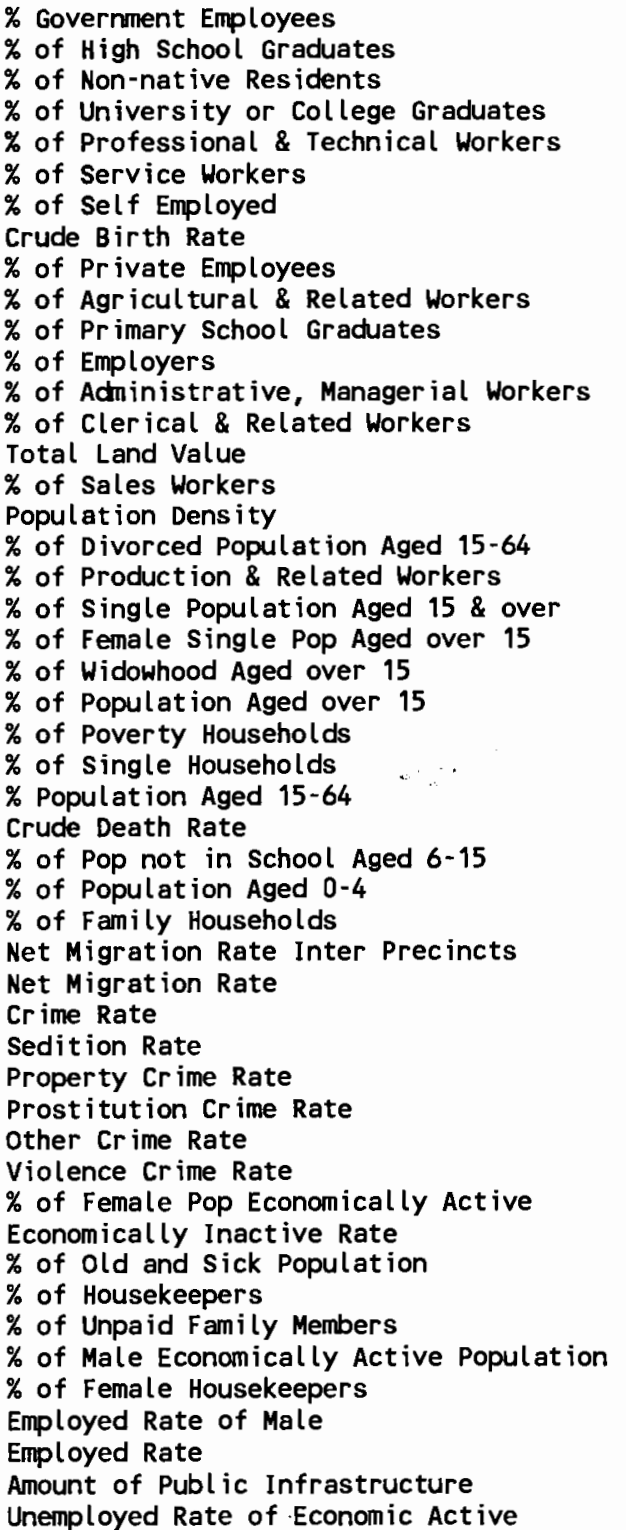 & $\begin{array}{l}0.22878006 \\
0.18130643 \\
0.63357531 \\
0.0409571 \\
0.06605066 \\
0.09102693 \\
0.1328555 \\
0.01911268 \\
0.57933917 \\
0.07385036 \\
0.2520502 \\
0.03184795 \\
0.03587 \\
0.00814237 \\
16932.95 \\
0.13540697 \\
26902.5167 \\
0.02657815 \\
0.3559998 \\
0.38155552 \\
0.33847985 \\
0.06045159 \\
0.03483842 \\
0.00649559 \\
0.1349937 \\
0.62854157 \\
0.00435107 \\
0.07449764 \\
0.10051506 \\
0.86346529 \\
-0.0091139 \\
-0.0127546 \\
0.05808082 \\
0.00123578 \\
0.03984865 \\
0.00203918 \\
0.00526949 \\
0.00968771 \\
0.41120701 \\
0.36427822 \\
0.06954814 \\
0.72769387 \\
0.02478559 \\
0.84096563 \\
0.78548853 \\
0.93229132 \\
0.92537654 \\
1.38529412 \\
0.06182236\end{array}$ & $\begin{array}{l}0.11896878 \\
0.0525104 \\
0.18105754 \\
0.03183123 \\
0.03907027 \\
0.04698417 \\
0.07146118 \\
0.00442382 \\
0.11676711 \\
0.07857329 \\
0.05231127 \\
0.03742804 \\
0.03617833 \\
0.01016978 \\
10025.7995 \\
0.07435319 \\
21796.9941 \\
0.00944285 \\
0.14438764 \\
0.04490446 \\
0.04138858 \\
0.01912959 \\
0.01388317 \\
0.00582465 \\
0.06551745 \\
0.0293394 \\
0.00313853 \\
0.07653606 \\
0.05263372 \\
0.07032722 \\
0.02592434 \\
0.04161958 \\
0.0405875 \\
0.00152611 \\
0.03023384 \\
0.00168431 \\
0.01205539 \\
0.0091012 \\
0.13159019 \\
0.0800538 \\
0.10231886 \\
2.07771492 \\
0.03189371 \\
0.07203195 \\
0.0845817 \\
0.05887047 \\
0.08498503 \\
1.24389538 \\
0.05606806\end{array}$ \\
\hline
\end{tabular}

